\title{
Oxidative tissue injury in multiple sclerosis is only partly reflected in experimental disease models
}

\author{
Cornelia Schuh • Isabella Wimmer • Simon Hametner • Lukas Haider • \\ Anne-Marie Van Dam · Roland S. Liblau • Ken J. Smith · Lesley Probert • \\ Christoph J. Binder · Jan Bauer · Monika Bradl · Don Mahad · Hans Lassmann
}

Received: 5 November 2013 / Revised: 22 January 2014 / Accepted: 17 February 2014 / Published online: 13 March 2014

(C) The Author(s) 2014. This article is published with open access at Springerlink.com

\begin{abstract}
Recent data suggest that oxidative injury may play an important role in demyelination and neurodegeneration in multiple sclerosis (MS). We compared the extent of oxidative injury in MS lesions with that in experimental models driven by different inflammatory mechanisms. It was only in a model of coronavirus-induced demyelinating encephalomyelitis that we detected an accumulation of oxidised phospholipids, which was comparable in extent to that in MS. In both, MS and coronavirus-induced encephalomyelitis, this was associated with massive microglial and macrophage activation, accompanied by the expression of the NADPH oxidase subunit p22phox but only sparse expression of inducible nitric oxide synthase (iNOS). Acute and chronic $\mathrm{CD}^{+}{ }^{+} \mathrm{T}$ cell-mediated experimental autoimmune encephalomyelitis lesions showed transient expression of p22phox and iNOS associated with inflammation. Macrophages in chronic lesions of antibody-mediated demyelinating encephalomyelitis showed lysosomal
\end{abstract}

Electronic supplementary material The online version of this article (doi:10.1007/s00401-014-1263-5) contains supplementary material, which is available to authorized users.

C. Schuh · I. Wimmer · S. Hametner · L. Haider · J. Bauer ·

M. Bradl $\cdot$ H. Lassmann $(\bowtie)$

Department of Neuroimmunology, Centre for Brain Research,

Medical University of Vienna, Spitalgasse 4, 1090 Vienna,

Austria

e-mail: hans.lassmann@meduniwien.ac.at

A.-M. Van Dam

Department of Anatomy and Neurosciences, VU University

Medical Center, Amsterdam, The Netherlands

R. S. Liblau

Inserm, U1043, CNRS, Centre de Physiopathologie de Toulouse Purpan (CPTP), U5282, Université de Toulouse, 31300 Toulouse, France activity but very little p22phox or iNOS expressions. Active inflammatory demyelinating lesions induced by $\mathrm{CD}^{+} \mathrm{T}$ cells or by innate immunity showed macrophage and microglial activation together with the expression of p22phox, but low or absent iNOS reactivity. We corroborated the differences between acute $\mathrm{CD} 4^{+} \mathrm{T}$ cell-mediated experimental autoimmune encephalomyelitis and acute MS lesions via gene expression studies. Furthermore, agedependent iron accumulation and lesion-associated iron liberation, as occurring in the human brain, were only minor in rodent brains. Our study shows that oxidative injury and its triggering mechanisms diverge in different models of rodent central nervous system inflammation. The amplification of oxidative injury, which has been suggested in MS, is only reflected to a limited degree in the studied rodent models.

Keywords Multiple sclerosis - Experimental autoimmune encephalomyelitis (EAE) · Oxidative injury · NADPH oxidase $\cdot$ Inducible nitric oxide synthase (iNOS) $\cdot$ Iron

\author{
K. J. Smith \\ Department of Neuroinflammation, University College London \\ Institute of Neurology, London, UK \\ L. Probert \\ Laboratory of Molecular Genetics, Hellenic Pasteur Institute, \\ Athens, Greece \\ C. J. Binder \\ Department of Laboratory Medicine, Medical University \\ of Vienna, Vienna, Austria \\ D. Mahad \\ Centre for Neuroregeneration, University of Edinburgh, \\ Edinburgh, UK
}




\section{Introduction}

Multiple sclerosis (MS) is a chronic inflammatory disease of the central nervous system (CNS) leading to focal plaques of primary demyelination in the white and grey matter, with astrocytic scar formation and profound axonal and neuronal degeneration [46]. Recent studies, including the same cases of autopsy tissue as the current study, suggest that oxidative injury may play a major role in the pathogenesis of MS [47]. In active lesions of the white matter and the cerebral cortex, demyelination and neurodegeneration were associated with the presence of oxidised lipids (oxidised phospholipids and malonedialdehyde) in myelin, apoptotic oligodendrocytes [33] and degenerating axons and neurons [26, 33]. Furthermore, nuclei of degenerating glia cells and neurons contained oxidised DNA [33]. Oxidative injury was associated with inflammation and oxidative burst in activated microglia and macrophages expressing p22phox as an essential subunit of NADPH oxidases [25, 26]. Mitochondrial injury $[11,54]$ as well as accumulation of iron in the ageing brain and its liberation from intracellular stores in active MS lesions [35] was suggested to further amplify the oxidative injury.

Experimental autoimmune encephalomyelitis (EAE) is currently the most widely used model of MS-like inflammatory demyelination in the CNS [30]. Many recent studies have used this model to unravel molecular mechanisms involved in inflammation, demyelination and neurodegeneration. This served as the basis for currently established anti-inflammatory treatments of the disease [95], but the success in developing neuroprotective therapies has so far been limited. This is particularly the case for progressive MS, for which currently no treatment is available $[32,47]$. The production and release of reactive oxygen and nitric oxide species have been shown to play a role in the pathogenesis of tissue injury in EAE [62, 78]. Whether the nature and extent of oxidative injury in rodent models of inflammatory demyelinating diseases are comparable to that observed in MS is currently unresolved. We, thus, analysed a large sample of acute and chronic experimental inflammatory brain diseases, including classical $\mathrm{CD}^{+}{ }^{+} \mathrm{T}$ cell-driven models of EAE, brain inflammation induced by MHC class I-restricted cytotoxic $\mathrm{T}$ cells, by innate immunity or by virus infection in direct comparison with MS lesions. Relying on identical tools as used for MS lesions, we found that inflammation-induced oxidative burst was only in part similar in experimental rodent models and MS. Furthermore, accumulation of oxidised phospholipids, which is associated with demyelination and neurodegeneration in MS lesions, was only observed in a model of virusinduced inflammatory demyelination.
Our data suggest that the mechanisms of tissue injury in MS are only incompletely reflected in the investigated rodent models and that new models will be necessary for the development and testing of neuroprotective therapy strategies intended to target oxidative injury.

\section{Materials and methods}

\section{MS patients and experimental models}

Our study was performed on archival formalin-fixed paraffin-embedded tissue of MS patients and on archival material derived from experimental animal models of brain inflammation and demyelination collected at the Centre for Brain Research during the last three decades. The study was approved by the Ethical Committee of the Medical University of Vienna (EK. Nos. 535/2004 and 213/06/2013). The MS study cohort contained autopsy tissue from 17 controls and $31 \mathrm{MS}$ cases, including 7 patients with acute MS, 3 patients with relapsing remitting MS (RRMS), 12 patients with secondary progressive MS (SPMS) and 9 patients with primary progressive MS (PPMS). The corresponding clinical data were already described in detail elsewhere [35]. Details on the sample of human autopsy cases and the basic pathology are provided in the supplementary data.

For the analysis of experimental models, we used rat and mouse tissues from former studies performed in collaboration with our laboratory. The different study designs and the pathological characterisation of the tissues have been described in detail in the respective previous publications $[1,21,44,80,85,87,92,97]$. Tissue blocks containing inflammatory lesions with active demyelination or neurodegeneration defined by the presence of macrophages with early myelin or neuronal degradation products were selected from a large collection. The following experimental models were analysed: acute EAE triggered by passive transfer of myelin basic protein reactive $\mathrm{CD} 4^{+} \mathrm{T}$ cells [1], chronic EAE induced in mice by active sensitisation with $\mathrm{MOG}_{35-55}$ peptide [87], chronic relapsing EAE induced in DA rats by active sensitisation with $\mathrm{MOG}_{1-125}$ [85], acute EAE induced by passive transfer of encephalitogenic $\mathrm{CD}^{+} \mathrm{T}$ cells [80], inflammatory demyelination induced by intraspinal injection of lipopolysaccharide [21, 56], demyelinating lesions induced in mice by cuprizone diet [92] and chronic inflammatory demyelinating disease following mouse hepatitis virus strain JHM (MHV-JHM) coronavirus infection $[3,44,94,97]$. Details on the experimental designs, clinical course and neuropathological alterations as well as animal numbers and time points of investigation for this study are provided in the supplementary data. For control reasons, brain, spinal cord and lymphatic tissues of young and aged Lewis rats, SD rats (untreated and saline 
Table 1 Primary antibodies and antigen retrieval procedures

\begin{tabular}{|c|c|c|c|c|c|}
\hline Antibody & Origin & Target & Dilution & Antigen retrieval & Source \\
\hline 8OHdG & Goat (pAB) & 8-Hydroxy-2'-deoxyguanosine & $1: 500$ & St (E) & Abcam; ab10802 \\
\hline APP & Mouse (mAb) & Amyloid precursor protein & $1: 1000$ & St $(\mathrm{C})$ & Chemicon; MAB348 \\
\hline CD3 & Rabbit (mAb) & $\mathrm{T}$ cells & $1: 2000$ & St $(E)$ & Neomarkers; RM-9107 \\
\hline CD68 & Mouse (mAb) & Phagocytic macrophages & $1: 100$ & St $(E)$ & Dako; M0814 \\
\hline E06 & Mouse (mAb) & Oxidised phospholipids & $1: 200$ & 0 & Avanti; 330001 \\
\hline ED1 & Mouse (mAb) & Rat CD68 & $1: 1000$ & St $(E)$ & Serotec; MCA341R \\
\hline GFAP & Rabbit (pAB) & Glial fibrillary acidic protein & $1: 3000$ & St $(\mathrm{E})$ & Dako; Z0334 \\
\hline Iba-1 & Rabbit (pAb) & $\begin{array}{l}\text { Ionised calcium binding adaptor } \\
\text { molecule } 1\end{array}$ & $1: 3000$ & St $(E)$ & Wako chemicals; 019-19741 \\
\hline iNOS anti-human & Rabbit (pAb) & Inducible nitric oxide synthase & $1: 30000$ & St $(E)$ & Chemicon; AB5384 \\
\hline iNOS anti-rat & Rabbit (pAb) & Inducible nitric oxide synthase & $1: 375$ & St $(\mathrm{C})$ & Chemicon; AB1631 \\
\hline Mac-3 & Rat (pAb) & Mouse CD68 & $1: 200$ & St $(\mathrm{C})$ & Serotec; MCA2293FB \\
\hline MBP & Rabbit (pAb) & Myelin basic protein & $1: 2500$ & 0 & Dako; A0623 \\
\hline MDA2 & Mouse (mAB) & Malonedialdehyde-lysine & $1: 1000$ & St $(\mathrm{E})$ & Palinski et al. [64] \\
\hline MOG Y10 and Z12 & Mouse (mABs) & Myelin oligodendrocyte glycoprotein & $1: 100$ & St $(\mathrm{C})$ & Piddlesten et al. [71] \\
\hline N 556 & Mouse (mAb) & Virus nucleocapsid & $1: 50$ & 0 & Wege et al. [93] \\
\hline Ox8 & Mouse (mAb) & Anti-rat CD8 & $1: 400$ & 0 & Seralab; MAS041 \\
\hline p22phox & Rabbit (pAb) & NADPH oxidase protein & $1: 100$ & St $(C)$ & Santa Cruz Biotech; sc-20781 \\
\hline PLP & Mouse (mAB) & Proteolipid protein & $1: 1000$ & St $(E)$ & Serotec; MCA839G \\
\hline TPPP/p25 & Rat (pAB) & $\begin{array}{l}\text { Tubulin polymerisation } \\
\text { promoting protein }\end{array}$ & $1: 3000$ & St $(\mathrm{E})$ & Hoftberger et al. [38] \\
\hline
\end{tabular}

Antibodies were used for human, rat and mouse tissues with the following exceptions: CD68 for human, ED1 and Ox8 for rat, Mac-3 for mouse tissue and iNOS anti-rat for rat and mouse

$O$ no antigen retrieval, $S t$ steaming using the indicated buffer for $1 \mathrm{~h}, C$ citrate buffer (pH 6.0), E EDTA buffer (pH 8.6), $m A b$ monoclonal antibody, $p A b$ polyclonal antibody

injected), DA rats and $C 57 B L / 6$ mice without inflammatory lesions were analysed.

Experimental material was routinely fixed in $4 \%$ paraformaldehyde (PFA) and embedded in paraffin. Basic neuropathological evaluation was based on haematoxylin/ eosin staining, Luxol Fast Blue myelin stain and Bielschowsky silver impregnation. Inflammation was detected by immunohistochemistry for CD3. Macrophage activation was studied using antibodies against Iba-1 (human, rat and mouse tissues), CD68 (human), ED1 (rat) and Mac-3 (mouse). Active demyelination was assessed by immunohistochemistry for myelin basic protein (MBP), myelin oligodendrocyte glycoprotein (MOG) and proteolipid protein (PLP). For the detection of oxidative injury, the following markers were used: E06 (recognising oxidised phospholipids), MDA2 (malonedialdehyde), 8OHdG (8-hydroxy-2 deoxyguanosine), p22phox (subunit of NADPH oxidase complexes), iNOS (Nos2; inducible nitric oxide synthase) and 3,3'-diaminobenzidine (DAB)-enhanced Turnbull blue reaction (non-haeme tissue iron). A detailed validation of the applied techniques showed suitability, comparable sensitivity and specificity in studies using rat, mouse and human material (Supplementary Figs. 1 and 2).
Immunohistochemistry

Sections were cut $(5 \mu \mathrm{m})$, routinely deparaffinised and rehydrated. Endogenous peroxidase activity was blocked in methanol with $0.02 \%$ hydrogen peroxide $\left(\mathrm{H}_{2} \mathrm{O}_{2}\right)$ for $30 \mathrm{~min}$. Antigen retrieval procedures and primary antibodies are listed in Table 1. Prior to staining, non-specific antibody binding was blocked by incubating the sections with $10 \%$ foetal calf serum (FCS) in Dako buffer (Dako). Primary antibodies were applied in $10 \%$ FCS/Dako buffer at $4{ }^{\circ} \mathrm{C}$ overnight. Secondary antibodies were applied for $1 \mathrm{~h}$ at room temperature (RT) in $10 \% \mathrm{FCS} /$ Dako buffer. Finally, the sections were incubated with avidin peroxidase (1:100, Sigma Aldrich) in $10 \%$ FCS/Dako buffer for $1 \mathrm{~h}$ at RT. Antibody binding was routinely visualised using DAB (Sigma Aldrich). The sections were counterstained with haematoxylin, dehydrated and mounted in eukitt.

For double labelling of E06 and TPPP/p25 for oligodendrocytes or GFAP for astrocytes, E06 primary antibody was applied, followed by alkaline phosphatase-conjugated anti-mouse secondary antibody (1:200, Jackson ImmunoResearch) incubation and fast blue development (blue reaction product). Subsequently, the sections were steamed 
in EDTA buffer followed by TPPP/p25 or GFAP primary antibody application, species-specific biotinylated anti-rat (1:1,500, Jackson ImmunoResearch) or anti-rabbit antibody $(1: 2,000$, Jackson ImmunoResearch), avidin-peroxidase incubation and development in amino ethylcarbazole reagent (red reaction product, for details see $[33,56]$ ). In case of E06 double staining with APP, E06 primary antibody incubation was followed by alkaline phosphataseconjugated anti-mouse secondary antibody and fast blue development. Subsequently, the sections were steamed in citrate buffer, followed by APP primary antibody application, biotinylated secondary antibody (1:500, Jackson ImmunoResearch) and avidin-peroxidase incubation and amino ethylcarbazole development. Double labelling of Ox8 and ED1 was performed starting with ED1 primary antibody application, biotinylated secondary antibody and avidin-peroxidase incubation and DAB development. Subsequently, the sections were incubated with Ox8 primary antibody which was followed by alkaline phosphataseconjugated anti-mouse secondary antibody and fast blue development.

Quantification of immunohistochemistry was performed by manual counting of $\mathrm{CD}^{+} \mathrm{T}$ cells or $\mathrm{APP}^{+}$axonal spheroids. $\mathrm{ED}^{+}, \mathrm{Iba}^{+} 1^{+}, \mathrm{p} 22 \mathrm{phox}^{+}, \mathrm{iNOS}^{+}$or iron-positive macrophages and microglia were quantified by densitometric analysis of pictures taken under standardised conditions (identical microscope settings controlled by white balance values) with a Reichert Polyvar 2 microscope using Nikon NIS-Elements D3.10. Pictures were captured with gain 1.2 and an exposure time of $6 \mathrm{~ms}$. Area fraction was determined using ImageJ. The stainings were quantified from equally sized regions of interest in all cases.

\section{Histochemistry for non-haeme tissue iron}

The DAB-enhanced Turnbull blue staining (TBB) protocol was applied as described [57]. Briefly, paraffin sections were routinely deparaffinised and incubated in ammonium sulphide ( $2 \%$ in distilled water; Merck) for 90 min. After thorough washing, the sections were treated with an aqueous solution of $10 \%$ potassium ferricyanide (Merck) in $0.5 \% \mathrm{HCl}$. Endogenous peroxidase was blocked in methanol with $0.01 \mathrm{M}$ sodium azide and $0.3 \%$ hydrogen peroxide for $60 \mathrm{~min}$. Tissue iron was visualised by a 20-min incubation in $0.025 \%$ DAB and $0.0005 \% \mathrm{H}_{2} \mathrm{O}_{2}$ in $0.1 \mathrm{M}$ phosphate buffer.

Densitometric quantification of iron and E06 stainings

Pictures were taken from slides stained for iron or E06 under standardised conditions as described above. Optical density was determined by ImageJ after converting the pictures to 8 -bit, inverting and setting the scale to $1,024=1$.
Whole-genome microarray analysis of human MS samples

Data have been deposited in NCBI's Gene Expression Omnibus (GEO Accession Number GSE32915). A comprehensive description of technical issues [25] and clinical data of the study cohort [35] have been published previously. Shortly summarised, the RNA quality of archival formalin-fixed paraffin-embedded tissue blocks containing white matter brain lesions from acute MS or control patients was determined by in situ hybridisation for PLP mRNA [8]. If a strong hybridisation signal within oligodendrocytes was detected after a short development time, consecutive $6-10 \mu \mathrm{m}$ sections were mounted on glass slides. Areas containing either periplaque white matter (3 cases), initial (pre-phagocytic) lesions (4 different lesions from 3 cases) $[4,56]$ or active lesions containing early myelin degradation products (5 different lesions from 4 cases) [10] were microdissected. Likewise, normal white matter material from four control cases was collected. Total RNA was isolated using the High Pure FFPE RNA Micro Kit (Roche). Subsequently, two amplification rounds were run using oligo(dT) primers and the Arcturus ${ }^{\circledR}$ Paradise $^{\circledR}$ FFPE Amplification Kit (Applied Biosystems ${ }^{\circledR}$ Life Technology ${ }^{\mathrm{TM}}$ ). RNA labelling, hybridisation to Agilent wholegenome microarrays $(4 \times 44 \mathrm{~K})$, microarray scanning as well as quantile normalisation of the raw data was carried out by Source BioScience imaGenes GmbH. For data analysis, relative quantities (RQ) were calculated for each individual gene by comparing the mean values of periplaque white matter, initial lesion and active lesion with the mean value of the NWM from controls. Various technical issues, for example problems due to formalin fixation-induced RNA strand breaks, issues of data validation and comparability with RT-qPCR data were extensively discussed in previous publications [25, 26]. A detailed description of gene and probe specifications is provided in Supplementary Table 3.

TaqMan ${ }^{\circledR}$ RT-qPCR gene expression analysis of rat EAE tissue

Lewis rats, either 4- or 8-month old, were injected intraperitoneally with MBP-specific T cells to trigger EAE. At the peak of disease (day 6) as well as during the recovery phase (day 10), 3 rats per age group were euthanized by inhalation of an overdose of $\mathrm{CO}_{2}$. For control reasons, 3 uninjected rats per age group were included. The animals were subsequently perfused with ice-cold PBS and the lumbar spinal cord was sampled, snap-frozen and kept at $-20{ }^{\circ} \mathrm{C}$ for short-term storage. RNA was routinely isolated from $40 \mathrm{mg}$ tissue using the peqGOLD Total RNA Kit and peqGOLD DNase I Digest Kit (Peqlab Biotechnologie $\mathrm{GmbH}$ ). RNA quantity and purity were 
determined spectrophotometrically (Nanodrop 2000; Peqlab Biotechnologie GmbH). Assessment of RNA quality was performed on a 2100 Bioanalyzer (Agilent Technologies Inc). With a mean RNA integrity number of 7.7 $( \pm 0.6)$, all samples were qualified for further processing. Using the High Capacity cDNA Reverse Transcription Kit (Applied Biosystems ${ }^{\circledR}$ Life Technologies ${ }^{\mathrm{TM}}$ ), 500 ng total RNA in a final reaction volume of $20 \mu \mathrm{l}$ was transcribed into cDNA employing the following thermal cycling conditions: $10 \mathrm{~min}$ at $25{ }^{\circ} \mathrm{C} ; 120 \mathrm{~min}$ at $37{ }^{\circ} \mathrm{C} ; 5 \mathrm{~min}$ at $85^{\circ} \mathrm{C}$. Thereof, $400 \mathrm{ng}$ RNA equivalents per sample were mixed together with appropriate amounts of TaqMan ${ }^{\circledR}$ Gene Expression Master Mix (Applied Biosystems ${ }^{\circledR}$ Life Technologies ${ }^{\mathrm{TM}}$ ) and loaded into each reservoir of Custom 384-Well Microfluidic Card TaqMan ${ }^{\circledR}$ Gene Expression Arrays (Applied Biosystems ${ }^{\circledR}$ Life Technologies ${ }^{\mathrm{TM}}$ ). According to the manufacturer's instructions, the microfluidic cards were centrifuged, sealed and subsequently run on a 7900HT Fast Real-Time PCR System employing SDS Software v2.4 (Applied Biosystems ${ }^{\circledR}$ Life Technologies ${ }^{\mathrm{TM}}$ ) and the following thermal cycling conditions: $2 \mathrm{~min}$ at $50{ }^{\circ} \mathrm{C} ; 10 \mathrm{~min}$ at $94.5^{\circ} \mathrm{C} ; 40$ cycles alternating $30 \mathrm{~s}$ at $97^{\circ} \mathrm{C}$ and $1 \mathrm{~min}$ at $59.7^{\circ} \mathrm{C}$.

Data were analysed using ExpressionSuite Software v1.0.3 (Applied Biosystems ${ }^{\circledR}$ Life Technologies ${ }^{\mathrm{TM}}$ ). Baseline and threshold settings were manually adjusted for each individual gene. The comparative $C_{\mathrm{T}}\left(\Delta \Delta C_{\mathrm{T}}\right)$ method was used to calculate relative quantities (RQ). Normalisation of $\mathrm{C}_{\mathrm{T}}$ values was based on five reference genes (18sRNA, X03205; Gapdh, NM_017008; Hprtl, NM_012583; Pgkl, NM_053291; Ppia, NM_017101). A detailed description of gene and TaqMan ${ }^{\circledR}$ array specifications is provided in Supplementary Table 4.

\section{Statistical analysis}

Descriptive statistics included median value and range, box plots and scatter plots. The linear dependence of samples was evaluated by Pearson correlation test. For comparison of multiple groups of normally distributed data one-way ANOVA followed by pair-wise comparisons and Tukey adjustment were calculated. In case of multiple comparison of not normally distributed data derived from densitometry, Kruskal-Wallis group testing was followed by Mann-Whitney $U$ post hoc tests and Bonferroni-Holm correction. Active lesions of experimental models were compared with the corresponding age control, although there was no significant difference detected between young and aged control animals (except for iron staining in basal ganglia which was considered separately). A $p$ value $\leq 0.05$ was considered as statistically significant. Statistical analyses were performed using PASW Statistics 18 (SPSS Inc.).

\section{Results}

Microglial oxidative burst, oxidative damage and iron accumulation in multiple sclerosis

Active lesions in multiple sclerosis (MS) are associated with perivascular and parenchymal inflammation dominated by $\mathrm{CD} 8^{+} \mathrm{T}$ cells [29]. Active demyelination and tissue injury in acute or relapsing remitting MS occur at sites of massive microglial activation and macrophage infiltration with macrophages containing early myelin degradation products as defined by Brück et al. [10] (Fig. 1d inserts; see also supplementary information). In patients with primary or secondary progressive MS, slowly expanding active lesions defined by a small rim of microglial activation and macrophage infiltration at the edge of demyelinated plaques are prominent [45].

In order to study microglial and macrophage activation, we analysed the accumulation of p22phox, which is an essential subunit of NADPH oxidase complexes. Since there is currently no microglia-specific marker available, we distinguished microglia from macrophages by their morphological phenotype. Thus, our study does not allow conclusions, whether macrophages within the lesions were derived from the microglial cell pool or from recruited monocytes. Individual microglia in the human control brain moderately expressed p22phox (Fig. 1a; Table 2), whereas p22phox was distinctly present in microglial nodules in the normal-appearing white matter (NAWM) of MS patients (Fig. 1b) and in areas of initial tissue injury (pre-phagocytic lesions) [4, 25] (Fig. 1c). Compared with initial active lesions, p22phox expression was low in later stages of active or inactive lesion centres and solely present in cells with a macrophage phenotype (Fig. 1d). The expression of iNOS in different MS subgroups was described before [25, 26]. We detected scattered microglia in the NAWM and in initial lesion areas expressing low levels of iNOS (Fig. 1e, f), whereas some microglia and macrophages in demyelinated MS lesions showed prominent expression of iNOS [56] (Fig. 1g; Table 2). Nevertheless, iNOS staining was generally much lower compared with p22phox.

Oxidative burst activation in microglia and macrophages in active MS lesions was reported to be associated with the presence of oxidised phospholipids [25, 26, 33]. Only few cells containing oxidised lipids (E06 or MDA2 immunoreactivity) were found in the normal white matter (NWM) of controls (Fig. 1h) and in inactive lesions (not shown). The highest numbers of immunoreactive cells were detected in classical initial active lesions (Fig. 1i-1). In active lesions of the white and grey matter, oxidised lipids were found in oligodendrocytes and myelin (Fig. 1i, j), in cytoplasmic granules within astrocytes (Fig. 1k) as well as in dystrophic axons and degenerating neurons (Fig. 11) [33]. 


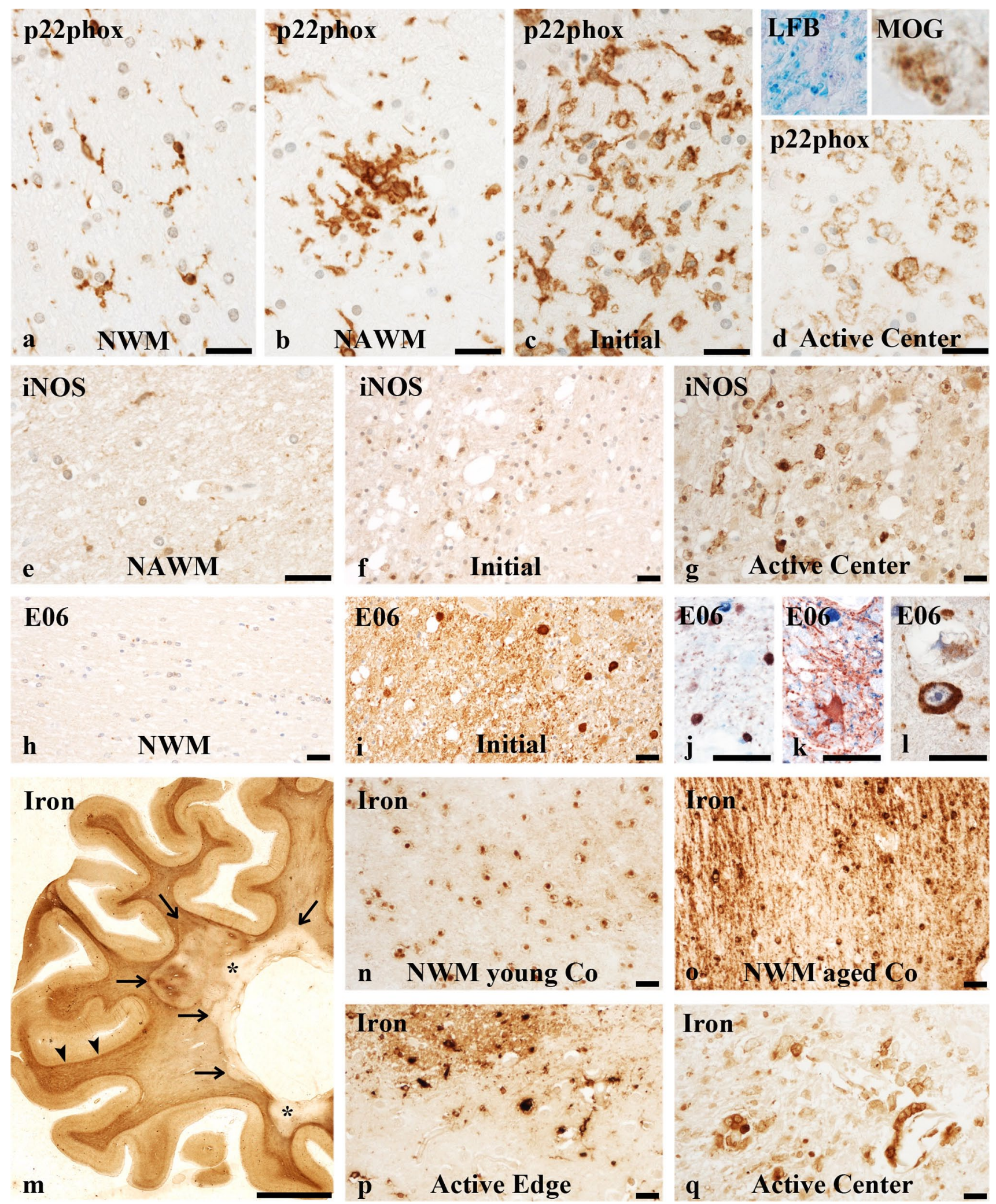

The liberation of iron from oligodendrocytes and myelin in active MS lesions is a potential amplification factor for oxidative injury [35] (Fig. 1m-q). As described before [34, 35], iron accumulates during ageing within oligodendrocytes in the human brain (Fig. 1n, o). Additionally, some microglia in aged controls showed reactivity for non-haeme iron [35]. In active MS lesions, iron-containing oligodendrocytes were lost and iron was 
4 Fig. 1 Oxidative burst, oxidative injury and iron accumulation in MS lesions. Expression of p22phox in the normal white matter (NWM) of a control brain (a), the normal-appearing white matter (NAWM; b), the zone of initial (pre-phagocytic) demyelination (c) and in the plaque centre of an active lesion (d) from an acute MS patient, defined by the presence of LFB and MOG reactive myelin degradation products in macrophages (inserts). Individual microglia in the control brain expressed p22phox. There was profound microglial activation in the NAWM with the formation of microglial nodules, a massive p22phox expression in initial areas of active demyelination and a low expression on macrophages containing myelin debris in the plaque centre. iNOS expression in acute MS in the NAWM (e) and in initial areas of demyelination (f) was weak and restricted to a few cells with microglial morphology. In the active plaque centre, iNOS was mainly expressed on macrophages (g). Immunoreactivity of E06 staining for oxidised phospholipids was low or absent in the NWM of controls (h) and very high in areas of initial demyelination in acute MS (i). Double staining for E06 (blue) and cell markers (brown) documented its presence in oligodendrocytes (stained for TPPPp $25 ; \mathbf{j}$ ) and cytoplasmic granules in astrocytes (stained for GFAP; k). Intense E06 reactivity was also found in the cytoplasm of cortical neurons, showing beading and fragmentation of their cell processes (I). Iron staining of the MS brain revealed profound iron accumulation in the subcortical white matter ( $\mathbf{m}$; arrowheads) and at the edge of active lesions (m; arrows) from a SPMS patient. Established lesions showed a reduced iron staining $(\mathbf{m}$; asterisks). Young control brains revealed a relatively low iron content mainly found in oligodendrocytes (n; age 30). The aged human control (o; age 84) and MS (m; age 57) brains displayed high amounts of non-haeme iron in oligodendrocytes and myelin. High iron content was present at the edge of an active lesion from a RRMS patient in microglia (p). Within the centre of an active lesion, the iron load was reduced and iron reactivity was mainly found in (perivascular) macrophages (q). Scale bar $50 \mu \mathrm{m}$ except for $\mathbf{m}=1 \mathrm{~cm}$

detected in the extracellular space [35]. Furthermore, iron within the lesions was taken up by microglia and macrophages (Fig. 1p, q) and to a lower degree by astrocytes and axons [35] (not shown). Our findings on the expression of p22phox and iNOS and the occurrence of oxidised lipids (E06) in MS are summarised in Table 2.

The expression of genes related to oxidative stress, mitochondria and iron metabolism differs between passive transfer EAE and active white matter MS lesions

In recently published whole-genome microarray analyses, we have already shown profound changes in the expression of genes related to oxidative stress, mitochondrial injury and iron metabolism within active white and cortical grey matter MS lesions [25, 26]. In the present study, we analysed the expression of these candidate genes in the lower spinal cords of young ( 4 months) and aged (8 months) Lewis rats suffering from $\mathrm{MBP}-$ specific $\mathrm{CD}^{+} \mathrm{T}$ cellinduced EAE via RT-qPCR, and analysed them together with the microarray data from active MS white matter lesions (Fig. 2).

At both investigated EAE time points (day 6, EAE peak; day 10 , recovery phase), we observed a massively upregulated expression of NADPH oxidase genes that was slightly damped in the older rat population (Fig. 2a). In contrast, the number of upregulated NADPH oxidase genes and the degree of upregulation differed markedly in active white matter MS lesions compared with EAE. iNOS (Nos2), a further initiator of oxidative/nitrative stress, was highly expressed in the acutely diseased rat spinal cords, whereas it was down-regulated in active white matter MS lesions. A high number of the mitochondrially encoded genes was at least twofold down-regulated in the MS lesions (Fig. 2c). In contrast, this pattern was not found in rat EAE tissue even at the peak of disease. Regarding the expression of iron metabolism-related genes (Fig. 2b), the picture for many genes was mutually exclusive: if the gene expression was altered during EAE, either no or a contrary expression change was observed in the human MS tissue and vice versa.

Taken together, the comparison of rat EAE spinal cord tissue with human active white matter MS lesions revealed rather more differences than similarities in the expression patterns of genes related to oxidative stress, mitochondria and iron metabolism. Oxidative stress, presumably inflammation induced, operates in both conditions studied. However, subsequent responses to oxidative damage and mitochondrial injury, as well as molecular changes regarding iron storage and release, seem to diverge.

To confirm these data on the basis of protein expression and to expand them to other models of inflammatory demyelination, we performed a detailed immunohistochemical analysis.

Microglial oxidative burst, oxidative injury and iron accumulation in various experimental models and MS patients diverge

\section{EAE induced by passive transfer of MBP-reactive T cells in Lewis rats}

Passive transfer of encephalitogenic $\mathrm{CD}^{+}{ }^{+} \mathrm{T}$ cells (Fig. 3ai) led to a monophasic acute inflammatory CNS disease, which started 3 days after $\mathrm{T}$ cell transfer, reached its peak after 6 days and was followed by a complete recovery of the animals [1]. The disease course was similar in young (2 months) and aged (14 months) animals when we transferred the same quantity of MBP-specific T cells (data not shown). At the peak of the disease, CNS lesions comprised pronounced $\mathrm{T}$ cell-mediated inflammation associated with microglia and macrophage activation and transient axonal dysfunction, but demyelination was sparse [1]. In comparison with young rats, the aged animals showed significantly lower numbers of infiltrating $\mathrm{CD}^{+} \mathrm{T}$ cells in the lumbar spinal cord (young $158.5 \pm 97.8$, old $58.4 \pm 8.3 \mathrm{CD}^{+}$ $\mathrm{T}$ cells per $\left.\mathrm{mm}^{2} ; p=0.005\right)$ but similar areas covered by 
Table 2 Quantification of markers for inflammation and oxidative injury in different experimental models for CNS inflammation and multiple sclerosis

\begin{tabular}{|c|c|c|c|c|c|c|c|c|c|c|}
\hline \multirow[t]{2}{*}{ Model } & \multicolumn{3}{|c|}{ Mechanism } & \multicolumn{7}{|c|}{ Active lesion } \\
\hline & & & & \multicolumn{2}{|c|}{ Iba-1 } & \multicolumn{2}{|c|}{ p22phox } & iNOS & E06 & Iron \\
\hline Acute pt EAE young & \multicolumn{3}{|c|}{$\mathrm{CD}^{+}{ }^{+} \mathrm{T}$ cells } & \multicolumn{2}{|c|}{$10.90(5.23)$} & \multicolumn{2}{|c|}{$10.46(3.66)$} & $2.25(2.10)$ & $122(44)$ & $0.00(0.01)$ \\
\hline Acute pt EAE aged & \multicolumn{3}{|c|}{$\mathrm{CD} 4^{+} \mathrm{T}$ cells } & \multicolumn{2}{|c|}{$8.59(4.87)$} & \multicolumn{2}{|c|}{$9.10(3.83)$} & $2.99(1.62)$ & $130(37)$ & $0.00(0.00)$ \\
\hline Chronic MOG EAE mouse & \multicolumn{3}{|c|}{$\mathrm{CD} 4^{+} \mathrm{T}$ cells } & \multicolumn{2}{|c|}{$11.12(17.66)$} & \multicolumn{2}{|c|}{$3.28(8.33)$} & $0.02(0.56)$ & $185(46)$ & $0.18(0.92)$ \\
\hline Chronic MOG EAE rat & \multicolumn{3}{|c|}{$\begin{array}{l}\mathrm{CD} 4^{+} \mathrm{T} \text { cells }+ \text { demyelinating } \\
\text { antibodies }\end{array}$} & \multicolumn{2}{|c|}{$9.33(16.18)$} & \multicolumn{2}{|c|}{$0.30(3.90)$} & $0.01(0.06)$ & $124(172)$ & $0.01(0.73)$ \\
\hline CD8 EAE & \multicolumn{3}{|c|}{$\mathrm{CD}^{+}{ }^{+} \mathrm{T}$ cells } & \multicolumn{2}{|c|}{$7.58(7.42)$} & \multicolumn{2}{|c|}{$1.17(2.53)$} & $0.00(0.31)$ & $233(97)$ & $0.05(0.32)$ \\
\hline LPS injection & \multicolumn{3}{|c|}{ Innate immunity } & \multicolumn{2}{|c|}{$6.90(17.30)$} & \multicolumn{2}{|c|}{$0.80(3.70)$} & $0.02(0.86)$ & $200(35)$ & $0.01(1.00)$ \\
\hline Cuprizone diet & \multicolumn{3}{|c|}{ Toxic demyelination } & \multicolumn{2}{|c|}{$11.97(7.03)$} & \multicolumn{2}{|c|}{$0.04(0.04)$} & $0.00(0.00)$ & $130(46)$ & $0.01(0.01)$ \\
\hline $\begin{array}{l}\text { Coronavirus MHV-JHM } \\
\text { encephalomyelitis }\end{array}$ & $\begin{array}{r}\text { Vir } \\
\text { in }\end{array}$ & $\begin{array}{l}\mathrm{CD} 8^{+} \mathrm{T} \text { cells, } \\
\text { immunity }\end{array}$ & & 15.8 & 3.16) & 3.7 & .73) & $0.00(0.09)$ & $644(138)$ & $0.01(0.70)$ \\
\hline Acute MS & Un & & & 12.6 & 8.86) & 8.6 & 2.12) & $0.47(2.58)$ & $553(313)$ & b \\
\hline & & NWM/NGM & & & & & & & & \\
\hline & & Iba-1 & $\mathrm{p} 221$ & & iNOS & & E06 & & Iron & \\
\hline & & & & & & & & & BG & $\mathrm{SC}$ \\
\hline Young control animals & n.p. & $2.55(1.69)$ & 0.00 & & 0.00 & $.00)$ & 125 & (48) & $0.03(0.04)$ & $0.01(0.02)$ \\
\hline Old control animals & n.p. & $3.28(2.98)$ & 0.00 & & 0.00 & $.00)$ & 110 & (39) & $2.94(2.08)$ & $0.01(0.02)$ \\
\hline Human controls & n.p. & $4.41(5.58)$ & 2.47 & $31)^{\mathrm{a}}$ & 0.04 & $.02)^{\mathrm{a}}$ & 336 & $(132)^{\mathrm{a}}$ & b & $\mathrm{b}$ \\
\hline
\end{tabular}

Quantification of Iba-1, p22phox, iNOS, oxidised phospholipids (E06) and iron staining in active lesions of different rodent models for CNS inflammation in comparison with acute MS cases and human controls. Depicted are values of median (range) derived from optical densitometry (area fraction for Iba-1, p22phox, iNOS and iron and integrated density for E06) of equally sized pictures taken under standardised conditions of the respective animal model or MS case. Bold numbers indicate a significant increase compared to control animals, or in case of MS compared to human controls, using Mann-Whitney $U$ post hoc tests and Bonferroni-Holm correction. In case of iron staining, lesions were compared with the respective control tissue

$N W M$ normal white matter, $N G M$ normal grey matter, $E A E$ experimental autoimmune encephalomyelitis, $p t$ passive transfer, $B G$ basal ganglia, $S C$ spinal cord, LPS lipopolysaccharide, n.p. not present, (young control animals $n=6$; old control animals $n=6$; acute EAE young $n=6$; acute EAE aged $n=8$; chronic MOG EAE mouse $n=15$; chronic MOG EAE rat $n=14$; CD8 EAE $n=6$; LPS injection $n=20$; cuprizone diet $n=5$; coronavirus encephalomyelitis $n=11$; acute MS $n=7$; human controls $n=6$ )

${ }^{a}$ A significant increase compared to animal controls. Iron staining in basal ganglia (BG) was significantly increased in old compared with young controls

${ }^{\mathrm{b}}$ Iron accumulation in MS and human controls was not quantified in the present study, as it is dependent on location and age as described elsewhere [35]

$\mathrm{ED}^{+}$macrophages (young $10.4 \pm 1.3 \%$, old $9.6 \pm 3.9 \%$ ). Additionally, we detected a significantly higher number of amyloid precursor protein (APP)-positive axonal spheroids in the lesions of aged animals (young $43.5 \pm 17.4$, old $58.5 \pm 8.3 \mathrm{APP}^{+}$spheroids per $\left.\mathrm{mm}^{2} ; p=0.039\right)$, which indicated a higher level of acute axonal injury.

At the peak of the disease, p22phox and iNOS expressions were low or absent in Iba- $1^{+}$cells with microglial morphology (Fig. 3a-c). However, we saw strong signals for p22phox and iNOS on cells with macrophage morphology in the lesions (Fig. 3b, c; Table 2). Furthermore, microglial nodules were completely absent from the NAWM. In the recovery phase of the disease, macrophages expressed Iba- 1 and the phagocytosis marker ED1 but had lost their p22phox and iNOS expressions (data not shown). Neither in young nor in aged animals was a specific staining for oxidised phospholipids detectable (Fig. 3d; Table 2). However, we found individual degenerating neurons in aged control and EAE rats that were specifically labelled for oxidised phospholipids (Fig. 3e) confirming that we were able to detect the epitope of E06 in animals using the same staining protocol as for MS tissue.

We did not detect any iron accumulation in the normalappearing white and grey matter in young control animals (2-6 months; Fig. 3g; Table 2). In aged rats (14 months), minor iron accumulation was restricted to the basal ganglia (Fig. 3f), the substantia nigra and the dentate nucleus of the cerebellum. As in humans, iron in aged rats mainly accumulated within oligodendrocytes and rarely in microglia (Fig. 3h). Within EAE lesions, individual iron-positive macrophages were found in the perivascular space (Fig. 3i). 


\section{a Oxidative stress}

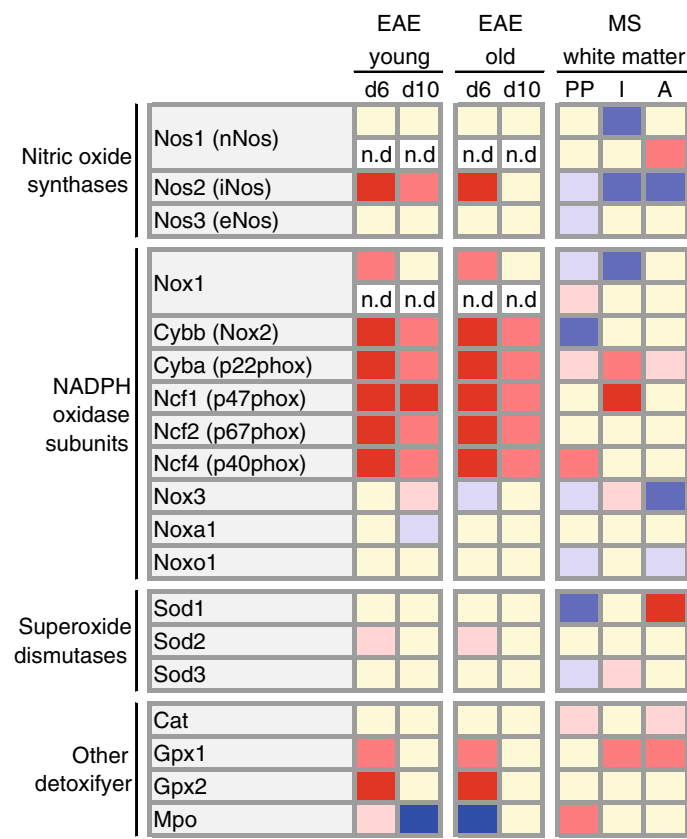

b Iron metabolism

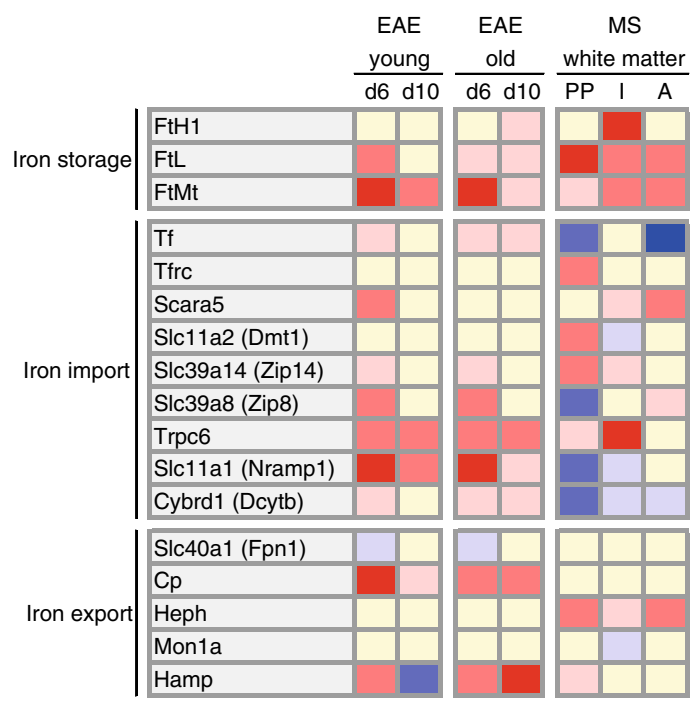

\section{Mitochondrially-encoded}

\begin{tabular}{|c|c|c|c|c|c|}
\hline & $\begin{array}{c}\text { EAE } \\
\text { young } \\
\end{array}$ & $\begin{array}{l}\text { EAE } \\
\text { old }\end{array}$ & \multicolumn{3}{|c|}{$\begin{array}{c}\text { MS } \\
\text { white matter }\end{array}$} \\
\hline & d6 $\mathrm{d} 10$ & d6 d10 & $\mathrm{PP}$ & 1 & $A$ \\
\hline Mt-Nd1 & & & & & \\
\hline Mt-Nd2 & & & & & \\
\hline Mt-Nd3 & & & & & \\
\hline Mt-Nd4 & & & & & \\
\hline Mt-Nd4I & & & n.d. & n.d. & n.d. \\
\hline Mt-Nd5 & & & & & \\
\hline Mt-Nd6 & & & & & \\
\hline Mt-Co1 & & & & & \\
\hline Mt-Co2 & & & & & \\
\hline Mt-Co3 & & & & & \\
\hline Mt-Atp6 & & & & & \\
\hline Mt-Atp8 & & & n.d. & n.d. & n.d. \\
\hline Mt-Cyb & & & & & \\
\hline
\end{tabular}

\section{d Mitochondria}
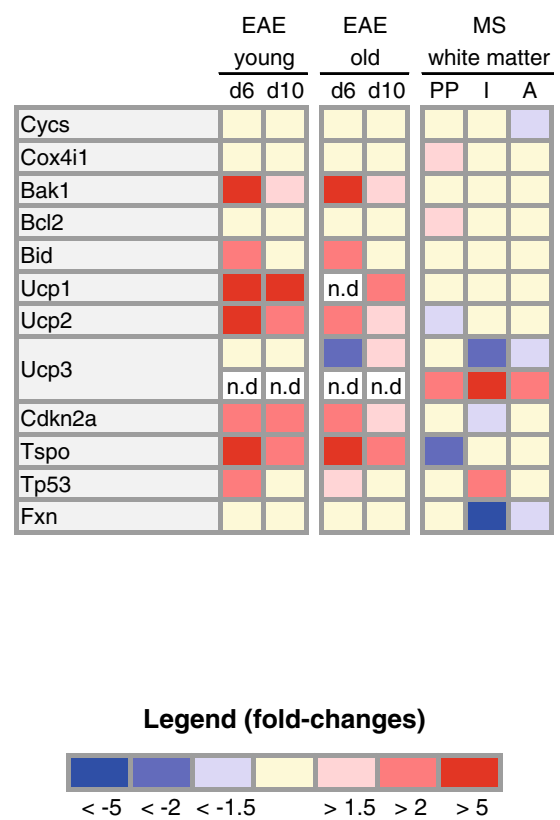

Fig. 2 Expression patterns of genes related to oxidative stress, mitochondria and iron metabolism differ between passive transfer EAE and active white matter MS lesions. The heat maps show colourcoded relative quantities of genes with known functions in oxidative stress pathways (a) and iron metabolism (b). Additionally, mitochondrially encoded genes (c) as well as nuclear-encoded genes with important mitochondrial functions (d) are depicted. The gene expression in lower spinal cords of young (4 months) and old (8 months) Lewis rats suffering from MBP-specific $\mathrm{T}$ cell-induced EAE was determined at two time points (day 6 , peak of disease; day 10 , recovery phase) via RT-qPCR. Transcriptional changes in periplaque white matter, initial (pre-phagocytic) lesions and active demyelinating lesions, derived from 3 or 4 acute MS cases, were investigated by whole-genome microarrays. Relative quantities were calculated for each individual gene by comparing the different time points and lesions with untreated age-matched Lewis rats or normal white matter from control cases, respectively. A detailed description of genes and primers/probes is presented in the supplementary data (Supplementary Table 3 and 4). $d 6$ day $6, d 10$ day $10, P P$ periplaque white matter, $I$ initial (pre-phagocytic) lesion, $A$ active demyelinating lesion, n.d. not determined 


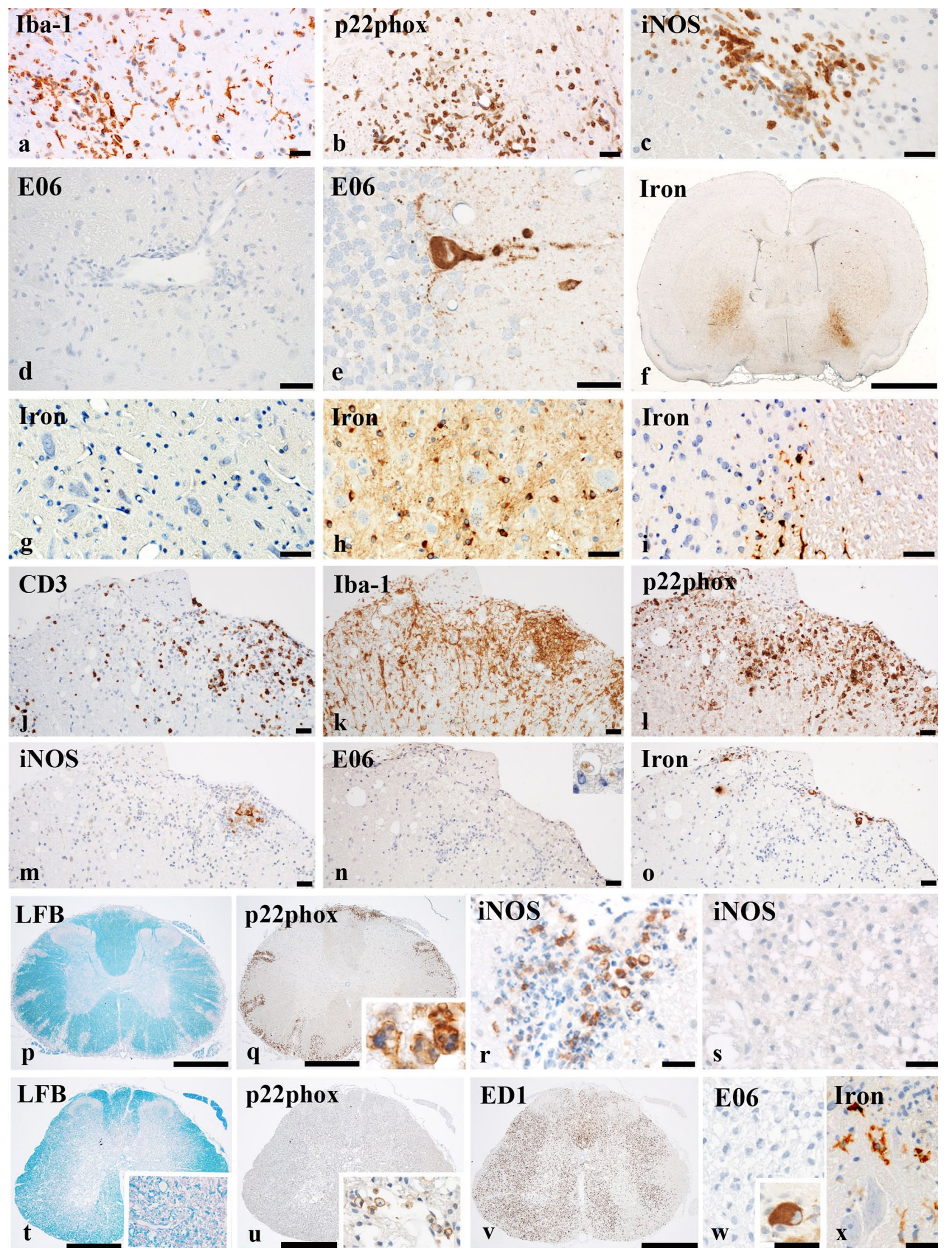


4 Fig. 3 Oxidative burst, oxidative injury and iron accumulation in acute and chronic models of $\mathrm{CD}^{+}{ }^{+} \mathrm{T}$ cell-mediated EAE. a-i Acute EAE induced by passive transfer of MBP-reactive encephalitogenic $\mathrm{CD}^{+} \mathrm{T}$ cells in aged Lewis rats (14-month old) at the peak of the disease ( 6 days after $T$ cell transfer). Inflammation was associated with profound microglial activation and macrophage infiltration at the lesions, immunoreactive for the pan-microglia/macrophage marker Iba-1 (a). In contrast, p22phox (b) and iNOS (c) expressions were more restricted and mainly found on cells with macrophage morphology. No E06 reactivity (oxidised phospholipids) was detected in inflammatory lesions (d) but was occasionally found in degenerating neurons (for instance in the cerebellar cortex of an aged control rat; e). Iron accumulated in the basal ganglia of a 14-month old EAE rat (f) while it was absent from the basal ganglia of 2-month old rats (g). In old rats, iron accumulated in oligodendrocytes and myelin in the basal ganglia (h). Within inflammatory EAE lesions, few macrophages and microglia showed iron accumulation (i). j-o Chronic relapsing/progressive EAE in $C 57 B L / 6$ mice immunised with $\mathrm{MOG}_{35-55}$. This model is characterised by large inflammatory demyelinating lesions with extensive axonal injury and loss in the spinal cord. The lesions contained abundant $\mathrm{CD}^{+} \mathrm{T}$ cells $(\mathbf{j})$ and $\mathrm{Iba}-1^{+}$ macrophages $(\mathbf{k})$. In addition, we found massive Iba-1 expression in cells with microglial morphology in the adjacent white and grey matter (k). The macrophages in the lesions also expressed p22phox (l), while iNOS expression was restricted to a limited number of perivascular macrophages $(\mathbf{m})$. E06 reactivity (oxidised phospholipids) was sparse or absent in the lesions (n), although there were few axonal spheroids with weak E06 staining (insert). Single lesion-associated meningeal macrophages accumulated iron (o). $\mathbf{p}-\mathbf{x}$ Chronic relapsing EAE in DA rats immunised with $\mathrm{MOG}_{1-125}$. Initial lesions presenting with a perivenous pattern of demyelination (p) showed scattered p22phox (q) and iNOS (r) expressions. p22phox in these lesions was mainly seen in granulocytes (q, insert). In contrast, in the chronic phase of the disease, there was an extensively active demyelination in the spinal cord grey and white matter (t) indicated by the presence of macrophages with myelin degradation products ( $\mathbf{t}$, insert). The lesions contained high numbers of $\mathrm{ED}^{+}$macrophages $(\mathbf{v})$ but their majority did not express p22phox (u) or iNOS (s). Only few macrophages in the lesions expressed p22phox (u, insert). Oxidised phospholipids did not accumulate in the active chronic lesions (w), but individual neurons with morphological evidence for retrograde degeneration were strongly labelled (w, insert). Within lesions, few macrophages and microglia showed iron accumulation (x). Scale bar $50 \mu \mathrm{m}$ except for $\mathbf{f}=0.25 \mathrm{~cm}$ and $\mathbf{j}, \mathbf{k}, \mathbf{n}, \mathbf{o}, \mathbf{p}=0.5 \mathrm{~mm}$

\section{Chronic EAE induced in C57BL/6 mice by active immunisation with $M O G_{35-55}$}

Chronic EAE induced in $C 57 B L / 6$ mice by active immunisation with $\mathrm{MOG}_{35-55}$ peptide is currently the most widely used animal model in MS research. In this model, disease starts between 10 and 15 days after sensitisation with an acute disease episode, which is similar to the disease peak of acute $\mathrm{T}$ cell transfer EAE described above. In our model, this was followed by a variable and short remission and a relapse of the disease with a progressive increase of clinical disease during the following weeks. Pathology in the relapsing/progressive stage of the disease is characterised by the presence of confluent inflammatory demyelinating lesions in the brain and spinal cord, associated with profound axonal injury and destruction. For our study, we analysed animals with active demyelination and neurodegeneration 21, 27 and 35 days after immunisation [87]. Active tissue injury was associated with massive infiltration of the tissue by $\mathrm{CD}^{+} \mathrm{T}$ cells (Fig. $3 \mathrm{j}$ ), profound microglia activation (Fig. 3k) and the presence of numerous macrophages containing early myelin degradation products in the lesions (not shown). p22phox expression was restricted to cells with a macrophage-like morphology, while activated Iba-1 reactive microglia in the perilesional and normal-appearing white matter were negative and no microglia nodules were detected (Fig. 31). Only single macrophagelike cells also expressed iNOS (Fig. 3m; Table 2). A weak reactivity for oxidised phospholipids was seen occasionally in dystrophic axons (Fig. 3n; Table 2). We did not observe any iron accumulation in oligodendrocytes or myelin, but single iron-containing perivascular or meningeal macrophages were detected in individual lesions (Fig. 3o; Table 2).

\section{Chronic relapsing demyelinating EAE in DA rats}

Active sensitisation of rats with $\mathrm{MOG}_{1-125}$ resulted in extensive primary inflammatory demyelination (Fig. 3p, t), which currently most closely reflects the pathology seen in multiple sclerosis [85]. In initial stages of active lesions (Fig. 3p), granulocytes and macrophages expressed p22phox (Fig. 3q) and few macrophages showed iNOS reactivity (Fig. 3r). In chronic active lesions (Fig. 3t), ED ${ }^{+}$ macrophages or microglia (Fig. 3v) were largely negative for p22phox (Fig. 3u; Table 2) and iNOS (Fig. 3s; Table 2) despite massive on-going demyelination (Fig. 3t). Furthermore, microglial nodules in the NAWM were absent in all disease stages.

Similar to acute passive transfer EAE, animals suffering from chronic relapsing EAE did not show any accumulation of oxidised phospholipids in active or inactive lesions (Fig. 3w; Table 2) with one exception. We observed small clusters of neurons in the spinal cord anterior horn showing reactivity for oxidised lipids and central chromatolysis in one individual animal out of 14 (Fig. 3w, insert). We could not detect any non-haeme iron staining in brain and spinal cord tissue of control animals but most EAE animals showed iron accumulation in perivascular macrophages in the lesions (Fig. 3x; Table 2). We neither detected p22phox nor iNOS expression in chronic inactive demyelinated plaques in this model, nor did we observe immunoreactivity for oxidised phospholipids (data not shown).

\section{Inflammatory demyelinating lesions induced by $C D 8^{+}$ cytotoxic T cells}

Since inflammation in MS lesions is dominated by $\mathrm{CD}^{+}$ $\mathrm{T}$ cells [2], we analysed oxidative injury in a $\mathrm{CD}^{+} \mathrm{T}$ 


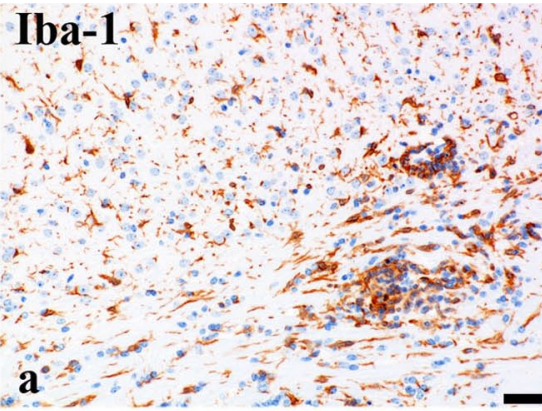

\section{p22phox}

iNOS
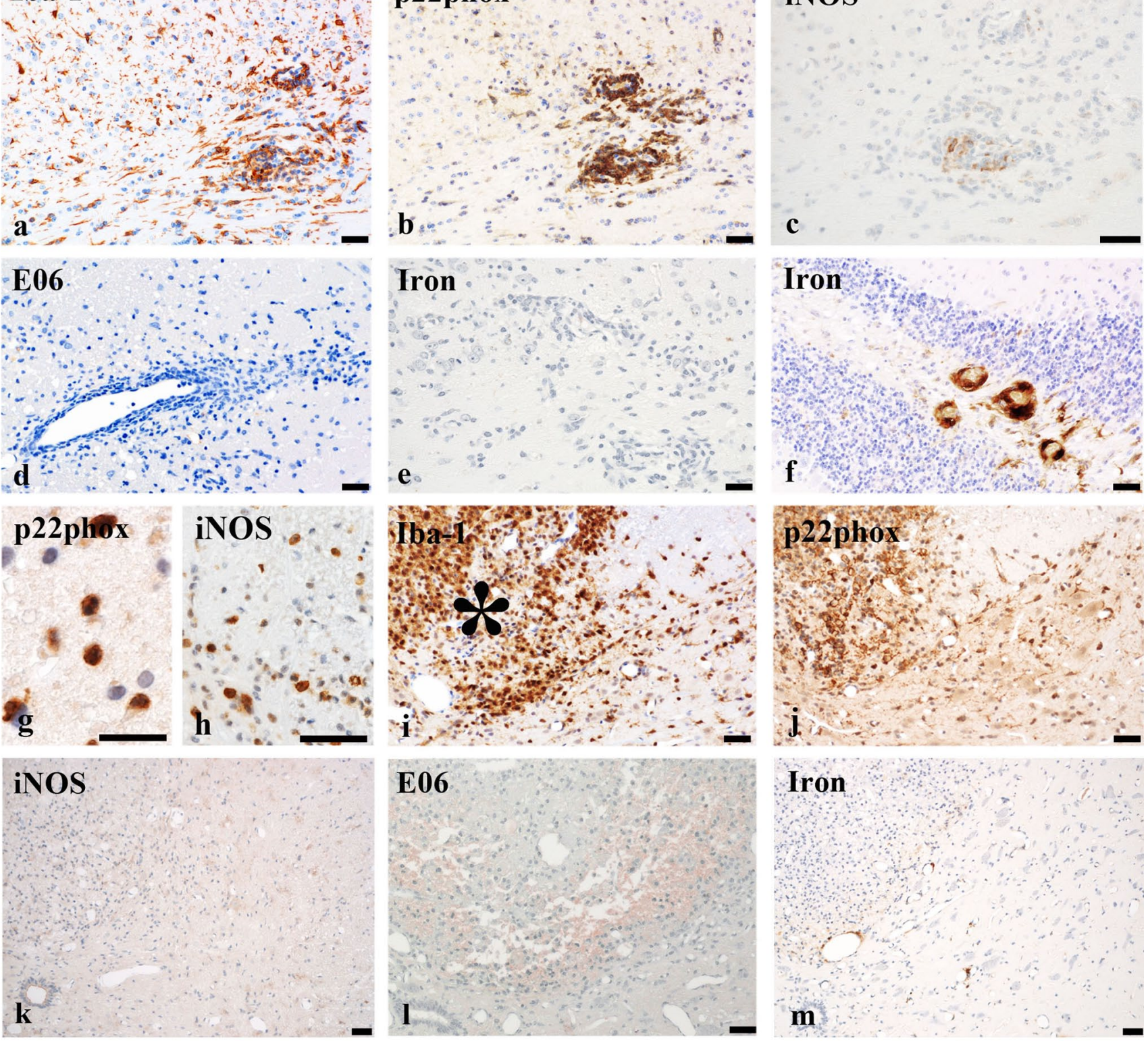

LFB

E06

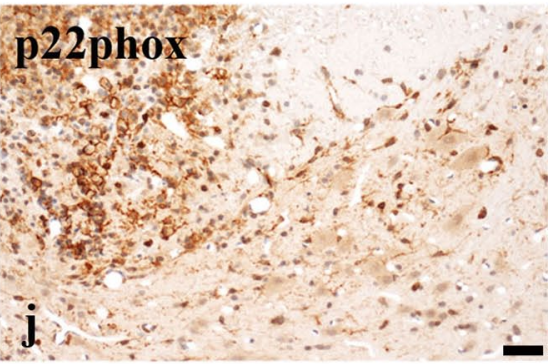

Iron

$\mathbf{m}$

p22phox n

iNOS

q

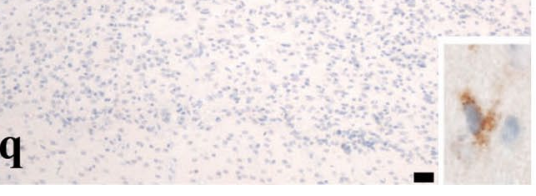

Mac-3

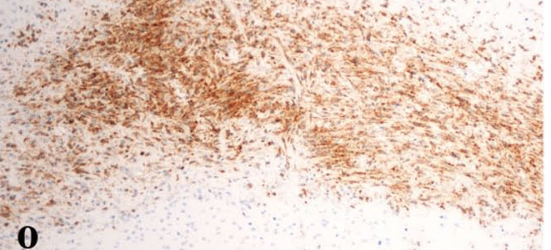

E06

$\mathbf{r}$

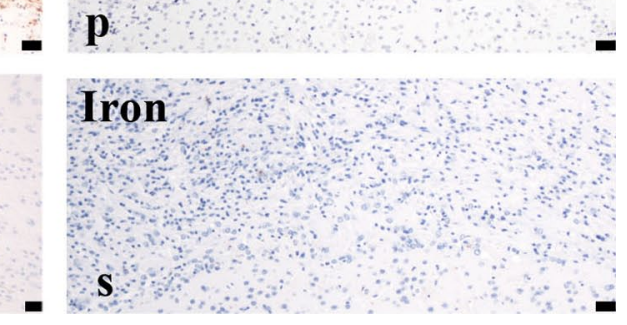


4 Fig. 4 Oxidative burst, oxidative injury and iron accumulation in $\mathrm{CD}^{+}{ }^{+} \mathrm{T}$ cell-mediated EAE, in innate immunity-driven inflammation and in toxic cuprizone-mediated demyelination. a-f Brain inflammation induced by $\mathrm{CD} 8^{+} \mathrm{T}$ cells. Perivascular inflammatory infiltrates were associated with massive microglial activation in the adjacent tissue (a; Iba-1). Perivascular inflammatory cells and to lower degree also the surrounding microglia highly expressed p22phox (b), while iNOS expression was minor and restricted to a few perivascular cells (c). The immunohistochemistry for oxidised phospholipids (E06; d) was negative. Iron deposition was lacking in most lesions (e) but occurred in few lesions within perivascular macrophages (f). g-m Inflammatory demyelinating lesions induced by local injection of LPS into the spinal cord dorsal column. In the early inflammatory stage ( 1 day after LPS injection), p22phox ${ }^{+}$granulocytes $(\mathbf{g})$ and iNOS $^{+}$macrophages (h) were present in the lesions. At the peak of active demyelination ( 9 days after LPS injection), lesions were densely infiltrated by macrophages and showed microglial activation at the lesion edge (i; Iba-1, asterisk). Macrophages in these lesions and, to a lower degree, microglia at the lesion edges showed expression of p22phox (j). Despite a very strong expression of $\mathrm{p} 22 \mathrm{phox}$ in active lesions $(\mathbf{j})$, the expression of iNOS was very low $(\mathbf{k})$. There was a weak reactivity for oxidised phospholipids in the lesions (l; E06). Individual perivascular macrophages were iron positive (m). $\mathbf{n}-\mathbf{s}$ Actively demyelinating lesion in the corpus callosum induced by cuprizone diet. Extensive loss of myelin was seen in the corpus callosum (n), which was densely packed with macrophages and microglia (o), although their majority did not express p22phox (p) and iNOS only very weakly (q). Additionally, there was no evidence for oxidised phospholipids (r; E06) or iron deposition (s) in the lesions. Scale bar $50 \mu \mathrm{m}$

cell-driven model leading to confluent demyelinated lesions (Fig. 4a-f) [80]. Microglial activation was prominent (Fig. 4a) but we could not detect any p22phox expression on microglia in the NAWM. In contrast, a substantial proportion of microglia as well as macrophages within and adjacent to lesions expressed p22phox (Fig. 4b; Table 2). iNOS reactivity was restricted to few perivascular macrophages (Fig. 4c; Table 2). We did not observe any microglia nodules in the NAWM (Fig. 4a). Also in this model, we did not find a significantly increased immunoreactivity for oxidised phospholipids in comparison to controls (Fig. 4d; Table 2). In the NAWM of the brain or the spinal cord as well as in the majority of active lesions, no iron accumulation was present (Fig. 4e; Table 2) but we detected perivascular macrophages with intense iron staining within single lesions in four out of seven animals studied (Fig. 4f).

\section{Inflammatory demyelinating lesions induced by innate immunity}

Recent observations suggest a major role of innate immune mechanisms in the pathogenesis of MS [4, 56]. Hence, we studied inflammatory demyelinating lesions induced by focal injection of bacterial LPS into the spinal cord white matter of rats [21] (Fig. $4 \mathrm{~g}-\mathrm{m}$ ). Inflammation started $8 \mathrm{~h}$ after LPS injection being dominated by $\mathrm{p} 22$ phox $^{+}$granulocytes (Fig. 4g), which were replaced by $\mathrm{p}_{22}$ phox $^{+}$ macrophages on day 3 (not shown). As shown before, some macrophages and microglia at these early inflammatory stages expressed iNOS (Fig. 3h) [56]. Demyelination and axonal injury occurred 7-9 days after LPS injection and reached a peak after 12-15 days [21]. Iba-1 immunohistochemistry showed densely packed macrophages within the demyelinating lesions (Fig. 4i). In actively demyelinating lesions, macrophages and few cells with microglia morphology showed moderate p22phox expression (Fig. 4j; Table 2). We did not find any microglial nodules in the NAWM. Only individual microglia and macrophages displayed very faint reactivity for iNOS (Fig. 4k; Table 2). Immunohistochemistry for oxidised phospholipids revealed very weakly E06-positive myelin in the lesions at day 12 (Fig. 41; Table 2). Iron stainings were negative with the exception of some perivascular iron-positive macrophages in the lesions (Fig. 4m; Table 2).

\section{Toxic demyelination induced by cuprizone diet}

Demyelinating lesions in mice fed with cuprizone-supplemented diet are regarded as a suitable model of demyelination in MS [41]. We analysed actively demyelinating lesions (Fig. 4n-s) showing oligodendrocyte apoptosis, microglial activation and astrocytic gliosis in the corpus callosum 35 days after disease induction [92]. The lesions contained densely packed Iba-1- and Mac-3-reactive cells with macrophage- or microglia-like morphology (Fig. 4o). However, the staining for p22phox was very faint (Fig. 4p; Table 2) and iNOS was only weakly expressed in single microglia (Fig. 4q; Table 2). Stainings for oxidised phospholipids did not show increased immunoreactivity in comparison to controls (Fig. 4r; Table 2). Furthermore, no iron accumulation was detected in the brain or spinal cord of cuprizone-fed animals (Fig. 4s; Table 2).

\section{Coronavirus-induced inflammatory demyelination}

Virus infections are suggested to be a causative factor in the development of MS [52]. We analysed brain lesions of Lewis rats infected with mouse hepatitis virus leading to a complex immune response including $\mathrm{CD}^{+} \mathrm{T}$ cells $[18$, 70] and specific anti-viral antibodies [51, 88, 97]. Intracerebral MHV-JHM coronavirus injections [3, 44, 94, 97] resulted in a panencephalitis with profound brain inflammation, global tissue damage and virus spread in neurons and glia [44, 97]. This early phase was followed by a subacute or chronic phase, in which virus infection was mainly seen in glia associated with inflammatory demyelination in the brain and spinal cord (Fig. 5a-i) [44, 94, 97]. Inflammation was dominated by $\mathrm{T}$ cells (Fig. 5d), mainly $\mathrm{CD}^{+}$cells (Fig. 5i), and activated macrophages and microglia (Fig. 5j-n; Table 2). Microglial activation was 


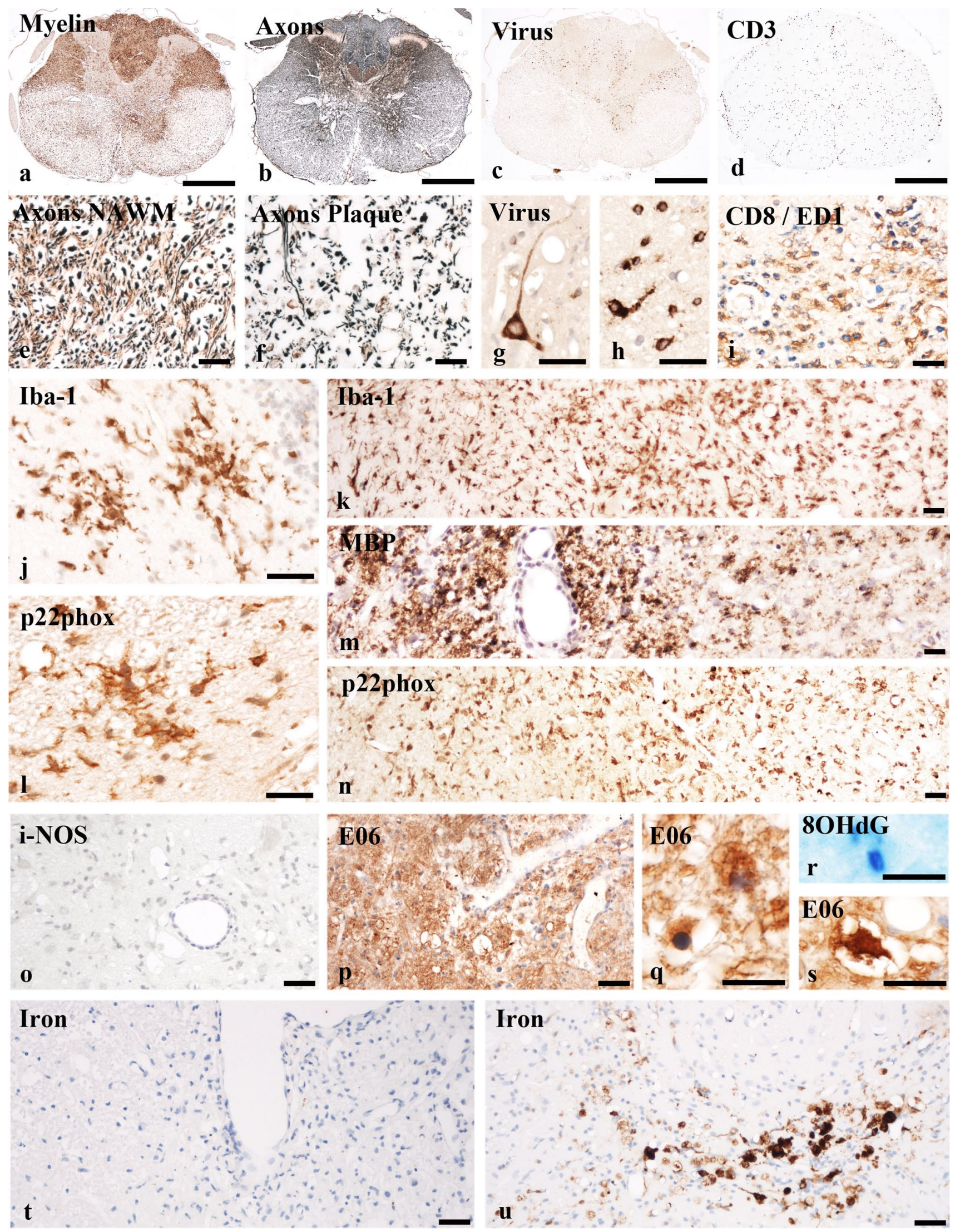


4Fig. 5 Oxidative burst, oxidative injury and iron accumulation in inflammatory demyelinating lesions in MHV-JHM coronavirusinduced encephalomyelitis. a-i Basic characterisation of inflammatory demyelinating lesions in the spinal cord of an infected Lewis rat with demyelinating encephalomyelitis after infection with MHVJHM coronavirus. There was extensive plaque-like demyelination (a; MBP) with relative preservation of axons (b and $\mathbf{f}$; e NAWM; Bodian silver impregnation). Virus antigen was present in the periplaque white and grey matter (c; immunohistochemistry for nucleocapsid protein $\mathrm{N}$ ) in neurons (g) as well as in glia cells in the white matter (h). Active demyelination was associated with profound $\mathrm{T}$ cellmediated inflammation (d), the majority of inflammatory cells being $\mathrm{CD}^{+} \mathrm{T}$ cells $($ blue $; \mathbf{i})$ and $\mathrm{ED} 1^{+}$macrophages $($brown $; \mathbf{i}) . \mathbf{j}-\mathbf{n}$ Determination of microglial activation in MHV-JHM coronavirus-induced lesions. Activated microglia formed microglial nodules in the NAWM reactive for Iba-1 (j) and p22phox (l). The edge of an active lesion is shown with immunocytochemistry for macrophages/microglia (Iba$1 ; \mathbf{k})$, for myelin (MBP; m) and for expression of NADPH oxidase (p22phox; n). Active demyelination was associated with profound microglial activation (k; Iba-1). Their numbers increased in the periplaque white matter (PPWM) towards the lesion edge (k; left side) showing the highest density at the zone of initial demyelination (k, middle) and decreasing towards the centre of the lesion, where many cells exhibited a macrophage phenotype (k; right side). Immunohistochemistry for $\mathrm{p} 22 \mathrm{phox}$ in serial-cut adjacent sections from the lesion (n) showed a staining pattern similar to that of Iba-1. iNOS expression was sparse in the lesions (o). p-u Accumulation of oxidative damage and iron in MHV-JHM coronavirus-induced lesions. Lesions showed abundant reactivity for oxidised phospholipids (p, q, s E06) in myelin (p), in cells with apoptotic nuclei $(\mathbf{q})$, in macrophage granules (q) and in axonal spheroids (s). In addition, nuclei within the lesions contained oxidised DNA (8OHdH reactivity; $\mathbf{r})$. Most lesions did not show iron deposition (t), although iron-positive perivascular macrophages accumulated in individual lesions (u). Scale bar $50 \mu \mathrm{m}$ except for $\mathbf{a}-\mathbf{d}=0.5 \mathrm{~mm}$

profound throughout the brain and spinal cord in all disease stages $[44,97]$. In contrast to all other models studied, we observed microglial nodules in the NAWM (Fig. 5j, $\mathrm{k})$. The number of microglia increased towards the lesion edge (Fig. 5k, m, left side), showed the highest density at the zone of initial demyelination (Fig. 5k, m, middle) and decreased towards the centre of the lesion (Fig. $5 \mathrm{k}$, m, right side), where many cells showed a macrophage morphology. Immunohistochemistry for $\mathrm{p} 22 \mathrm{phox}$ in serial-cut adjacent sections revealed a staining pattern rather similar to that of Iba-1 in the NAWM (Fig. 5l) and the lesion (Fig. 5n; Table 2). p22phox expression was most profound in active lesions and the adjacent NAWM, while it was low on macrophages in the inactive lesion centre (Fig. 5m, n). Expression of iNOS was rare or absent and, if present, only found in individual macrophage-like cells (Fig. 5o; Table 2). Strikingly, we found intense staining for E06-positive oxidised phospholipids within active lesions (Fig. 5p, q, s) and, to a lesser extent, in the NAWM. Additionally, we detected nuclear stainings of oxidised DNA in the lesions (Fig. 5r, 8OHdG). Quantification of E06 immunohistochemistry by optical densitometry revealed a significantly higher density of E06 staining in coronavirus-induced lesions than in control rats (Table 2). Iron accumulation was restricted to perivascular macrophages within the lesions (Fig. 5t, u). Our observations describing p22phox and iNOS expressions, detection of oxidised lipids (E06) and iron accumulation in MHV-JHM coronavirus-induced inflammatory demyelination as well as the other rodent models are highlighted in Table 2.

\section{Discussion}

In the present study, we show notable differences between MS and its different animal models regarding microglial activation, oxidative injury and iron accumulation in the undiseased CNS as well as within active inflammatory demyelinating lesions (Table 2). We found that the expression of enzymes involved in oxygen and nitric oxide radical production in cells with microglia or macrophage phenotype is different depending on the primary nature of the inflammatory response. As shown before, enzymes implicated in oxygen and nitric oxide radical cascades are induced in the inflammatory infiltrates of $\mathrm{CD}^{+}{ }^{+} \mathrm{T}$ cellmediated EAE [16, 43, 58, 78, 89, 90]. As observed in our study, they were mainly expressed in cells with macrophage morphology [63, 89]. Nitric oxide and its related reactive species in EAE lesions may serve anti-inflammatory functions $[6,22,79]$ or, in combination with oxygen radicals, may promote axonal injury $[1,13,60]$ via the formation of peroxynitrite $[9,17]$. We found that the above-mentioned macrophage and microglia activation patterns were different in chronic $\mathrm{CD}^{+}{ }^{+} \mathrm{T}$ cell-driven EAE and in models of CNS inflammation induced by $\mathrm{CD} 8^{+} \mathrm{T}$ cells or by innate immunity (LPS injection into the spinal cord white matter). In these situations at the time of active myelin destruction, NADPH oxidase subunit p22phox was mainly seen in macrophages, while iNOS expression was minor or absent. Furthermore, in active inflammatory demyelinating lesions induced by myelin-reactive antibodies or by the toxin cuprizone, very little expression of p22phox or iNOS was found, despite high expression of the phagocytosis-related markers ED1 (in rats) or Mac-3 (in mice). These findings were unexpected since pro-inflammatory cytokines, which are anticipated to be present in the lesions, evoked upregulation of NADPH oxidase and iNOS expression in microglia in vitro $[12,49,58]$. Furthermore, iNOS expression in the model of MHV-JHM coronavirus-induced inflammatory demyelination was reported in infiltrating macrophages of acute lesions and astrocytes in chronic lesions [31]. However, we did not find any astrocytic staining in our experimental setup. Our data support the view that the activation of microglia in a situation of an integrated immune response in vivo is more complex compared with the situation in vitro $[5,15,76]$. This possibly reflects the fact that 
the induction of NADPH oxidases is regulated by multiple additional factors such as Toll-like receptor activation [50], certain putative anti-inflammatory cytokines $[61,65,66]$, cholesterol load [75], thrombin [14], divalent cations [37, 40] and intracellular sodium accumulation [39]. All these factors are likely to contribute to a complex inflammatory process like that present in MS.

Oxidative injury and mitochondrial damage have been shown to play a role in neurodegeneration in EAE. Treatments targeting oxidative injury or protecting mitochondria were shown to be beneficial $[27,55,62,73,83]$. The presence of antibodies recognising oxidised phospholipids was demonstrated in MS and EAE [74]. In contrast, there are also antioxidant treatments that failed to attenuate EAE [24]. Both the presence of oxidised lipids and proteins as well as of antibodies against oxidised epitopes may have pro- and anti-inflammatory properties [19, 20, 23, 74].

The lack of accumulation of oxidised phospholipids presented in our study does not exclude oxidative injury in the respective models. Our data, however, show a major quantitative difference in the extent of oxidative injury between MS lesions and the majority of the studied experimental models of CNS inflammation and demyelination. Several possible explanations may serve as the basis for this observation. In the normal human brain, there is already moderate expression of NADPH oxidases and iNOS in microglia, which is absent in rodents. In contrast to humans, experimental animals are housed under highly standardised conditions and, therefore, peripheral immune stimulation due to infections is unlikely [68]. Furthermore, microglial activation occurs in the human brain as an age-related process $[53,86]$. In addition, factors related to ageing as well as the accumulation of lesion burden may amplify oxidative injury in the CNS of MS patients. One of these possible factors could be iron accumulation in oligodendrocytes and myelin, which occurs in humans during ageing [34]. Iron is suggested to promote oxidative injury when liberated from degenerating oligodendrocytes or myelin during demyelination [35]. Our study shows that iron accumulation in oligodendrocytes and myelin in the brain occurs only to a moderate degree in aged rodents and, if present at all, is restricted to the brain stem nuclei. Thus, the age-dependent physiological iron accumulation in the human brain is only poorly reflected in the normal rodent brain. This may relate to the much shorter life span of the animals. When the iron load in the rodent CNS is increased by knockout of a gene associated with iron detoxification and mobilisation (ceruloplasmin), traumatic spinal cord injury leads to increased free radical-mediated damage, impaired functional recovery and increased neurodegeneration [77]. Animals with dysfunctional hephaestin, a molecule involved in iron efflux, show deficits in motor performance with age [82]. In the course of brain inflammation, however, we found iron accumulation in macrophages possibly due to leakage of blood in active inflammatory lesions [28]. Moreover, iron chelator treatments of animals suffering from EAE ameliorate the disease $[7,48,59,67]$. This may be due to a decrease of oxidative stress and an inhibition of immune cell proliferation [59]. However, it is important to note that the iron load in the brain parenchyma of humans is remarkably higher than that of animals and likewise the resulting oxidative stress.

Furthermore, the accumulation of lesional burden in chronic diseases may play a role in the induction or propagation of lesions. Chronic pro-inflammatory microglial activation may be further amplified by retrograde degeneration due to distant chronic lesions with axonal and neuronal loss. Indeed, a recent neuropathological study suggests that cortical areas in the MS brain, which are connected with distant lesion sites, are more likely to develop new demyelinating lesions than other cortical regions [42]. However, extensive demyelination, axonal loss and retrograde degeneration, which are present in chronic EAE in DA rats [85], did not lead to oxidative burst activation in the normalappearing grey and white matter.

The only experimental model, in which we found an accumulation of oxidised phospholipids to an extent similar to that in MS patients, was the chronic inflammatory demyelination induced by brain infection with the MHV-JHM coronavirus. This model shares several features with MS. It is a chronic progressive inflammatory disease of the CNS, which leads to large plaques of primary demyelination with variable axonal loss and diffuse neurodegeneration in the NAWM [3, 97]. As in MS, inflammation is dominated by $\mathrm{CD}^{+} \mathrm{T}$ cells $[18,70]$ with profound microglial and macrophage activation [96] and clusters of activated microglia (microglial nodules) in the NAWM, which are highly characteristic of MS pathology [4, 72, 91]. Mechanisms of tissue injury in this model are apparently complex involving $\mathrm{CD}^{+}$and $\mathrm{CD}^{+}{ }^{+} \mathrm{T}$ cells $[18,36,69,70,84]$ and specific anti-viral antibodies [51, 88, 97]. In addition, chronic persistent virus infection in the CNS may provide an additional stimulus for microglial activation through Toll-like receptors. Whether the extensive oxidative injury found in MHVJHM coronavirus-induced encephalomyelitis is also present in other virus-induced models of chronic inflammatory demyelinating disease, such as Theiler's murine encephalomyelitis virus (TMEV) or canine distemper virus-induced encephalomyelitis, or is a specific feature of the MHV-JHM coronavirus-induced disease awaits further investigation. The chronicity of the inflammatory stimulus present in the MHV-JHM coronavirus model may be one factor that lends similarity of the pathology with that of MS.

We think that our findings may have major implications for the development of new therapeutic strategies for MS. Due to the notable differences observed in the mechanisms 
and extent of tissue injury between MS and current EAE models, the testing of neuroprotective treatments in EAE may not provide the answers necessary for predicting the outcome in patients. As an example, therapies aiming at stimulating endogenous antioxidant defence mechanisms, for instance by inducing the Nrf2 pathway [81], may be quite effective in a situation of moderate oxidative stress such as the one in classical EAE models. However, they might be ineffective or even counterproductive when oxidative injury is very extensive and endogenous defence mechanisms may have already reached a plateau. Thus, it will be important to create new experimental models that mimic the oxidative damage in MS more closely than those currently available. Chronic viral models of inflammatory demyelination may be more suitable. In addition, we encourage that transgenic animals over-expressing NADPH oxidases in microglia, with pre-existing defects in mitochondrial function or with an excessive brain iron load, should be developed. However, most important may be the chronicity of a sustained and severe inflammatory stimulus. This may finally result in cumulative effects of oxidative damage, which may trigger or become amplified by multiple factors, such as chronic microglia activation, oxygen radical production by injured mitochondria [11] as well as by age-dependent iron accumulation in the prime targets of MS tissue damage, the oligodendrocytes and myelin [35].

Acknowledgments We thank Marianne Leisser, Ulrike Köck and Angela Kury and for their excellent technical assistance. Further, we want to acknowledge Martin Bilban and Markus Jeitler (Department of Laboratory Medicine, Medical University of Vienna) for measuring RNA integrity, Martin Svoboda (Department of Pathophysiology and Allergy Research, Center for Pathophysiology, Infectiology and Immunology, Medical University of Vienna) for his expertise in TaqMan ${ }^{\circledR}$ arrays and Barbara Scheiber-Mojdehkar (Department of Medical Chemistry, Medical University of Vienna) for sharing the method of ferrozene assay with us. This project was funded by the Austrian Science Fund (projects P24245-B19 and W1205-B09, CCHD).

Conflict of interest No conflict of interest related to this study is reported by the authors.

Open Access This article is distributed under the terms of the Creative Commons Attribution License which permits any use, distribution, and reproduction in any medium, provided the original author(s) and the source are credited.

\section{References}

1. Aboul-Enein F, Weiser P, Hoftberger R, Lassmann H, Bradl M (2006) Transient axonal injury in the absence of demyelination: a correlate of clinical disease in acute experimental autoimmune encephalomyelitis. Acta Neuropathol 111(6):539-547. doi:10.1007/s00401-006-0047-y

2. Babbe H, Roers A, Waisman A, Lassmann H, Goebels N, Hohlfeld R, Friese M, Schroder R, Deckert M, Schmidt S, Ravid R, Rajewsky K (2000) Clonal expansions of $\mathrm{CD}^{8(+)} \mathrm{T}$ cells dominate the $\mathrm{T}$ cell infiltrate in active multiple sclerosis lesions as shown by micromanipulation and single cell polymerase chain reaction. J Exp Med 192(3):393-404

3. Barac-Latas V, Suchanek G, Breitschopf H, Stuehler A, Wege H, Lassmann H (1997) Patterns of oligodendrocyte pathology in coronavirus-induced subacute demyelinating encephalomyelitis in the Lewis rat. Glia 19(1):1-12

4. Barnett MH, Prineas JW (2004) Relapsing and remitting multiple sclerosis: pathology of the newly forming lesion. Ann Neurol 55(4):458-468. doi:10.1002/ana.20016

5. Boche D, Perry VH, Nicoll JA (2013) Review: activation patterns of microglia and their identification in the human brain. Neuropathol Appl Neurobiol 39(1):3-18. doi:10.1111/nan.12011

6. Bogdan C (2001) Nitric oxide and the immune response. Nat Immunol 2(10):907-916. doi:10.1038/ni1001-907

7. Bowern N, Ramshaw IA, Clark IA, Doherty PC (1984) Inhibition of autoimmune neuropathological process by treatment with an iron-chelating agent. J Exp Med 160(5):1532-1543

8. Breitschopf H, Suchanek G, Gould RM, Colman DR, Lassmann H (1992) In situ hybridization with digoxigenin-labeled probes: sensitive and reliable detection method applied to myelinating rat brain. Acta Neuropathol 84(6):581-587

9. Brown GC (2007) Mechanisms of inflammatory neurodegeneration: iNOS and NADPH oxidase. Biochem Soc Trans 35(Pt 5):1119-1121. doi:10.1042/BST0351119

10. Bruck W, Porada P, Poser S, Rieckmann P, Hanefeld F, Kretzschmar HA, Lassmann H (1995) Monocyte/macrophage differentiation in early multiple sclerosis lesions. Ann Neurol 38(5):788796. doi:10.1002/ana.410380514

11. Campbell GR, Ziabreva I, Reeve AK, Krishnan KJ, Reynolds R, Howell O, Lassmann H, Turnbull DM, Mahad DJ (2011) Mitochondrial DNA deletions and neurodegeneration in multiple sclerosis. Ann Neurol 69(3):481-492. doi:10.1002/ana.22109

12. Cheret C, Gervais A, Lelli A, Colin C, Amar L, Ravassard P, Mallet J, Cumano A, Krause KH, Mallat M (2008) Neurotoxic activation of microglia is promoted by a nox1-dependent NADPH oxidase. J Neurosci 28(46):12039-12051. doi:10.1523/JNEUROSCI.3568-08.2008

13. Choi SH, Aid S, Kim HW, Jackson SH, Bosetti F (2012) Inhibition of NADPH oxidase promotes alternative and anti-inflammatory microglial activation during neuroinflammation. J Neurochem 120(2):292-301. doi:10.1111/j.1471-4159.2011.07572.x

14. Choi SH, Lee DY, Kim SU, Jin BK (2005) Thrombin-induced oxidative stress contributes to the death of hippocampal neurons in vivo: role of microglial NADPH oxidase. J Neurosci 25(16):4082-4090. doi:10.1523/JNEUROSCI.4306-04.2005

15. Colton C, Wilcock DM (2010) Assessing activation states in microglia. CNS Neurol Disord: Drug Targets 9(2):174-191

16. Cross AH, Keeling RM, Goorha S, San M, Rodi C, Wyatt PS, Manning PT, Misko TP (1996) Inducible nitric oxide synthase gene expression and enzyme activity correlate with disease activity in murine experimental autoimmune encephalomyelitis. J Neuroimmunol 71(1-2):145-153

17. Cross AH, Manning PT, Stern MK, Misko TP (1997) Evidence for the production of peroxynitrite in inflammatory CNS demyelination. J Neuroimmunol 80(1-2):121-130

18. Dandekar AA, Anghelina D, Perlman S (2004) Bystander CD8 T-cell-mediated demyelination is interferon-gamma-dependent in a coronavirus model of multiple sclerosis. Am J Pathol 164(2):363-369

19. Dasgupta A, Zheng J, Perrone-Bizzozero NI, Bizzozero OA (2013) Increased carbonylation, protein aggregation and apoptosis in the spinal cord of mice with experimental autoimmune encephalomyelitis. ASN Neuro 5(1):e00111. doi:10.1042/AN20120088

20. Feige E, Mendel I, George J, Yacov N, Harats D (2010) Modified phospholipids as anti-inflammatory compounds. Curr Opin Lipidol 21(6):525-529. doi:10.1097/MOL.0b013e32833f2fcb 
21. Felts PA, Woolston AM, Fernando HB, Asquith S, Gregson NA, Mizzi OJ, Smith KJ (2005) Inflammation and primary demyelination induced by the intraspinal injection of lipopolysaccharide. Brain 128(Pt 7):1649-1666. doi:10.1093/brain/awh516

22. Fenyk-Melody JE, Garrison AE, Brunnert SR, Weidner JR, Shen F, Shelton BA, Mudgett JS (1998) Experimental autoimmune encephalomyelitis is exacerbated in mice lacking the NOS2 gene. J Immunol 160(6):2940-2946

23. Ferretti G, Bacchetti T (2011) Peroxidation of lipoproteins in multiple sclerosis. J Neurol Sci 311(1-2):92-97. doi:10.1016/j.jns.2011.09.004

24. Fiebiger SM, Bros H, Grobosch T, Janssen A, Chanvillard C, Paul F, Dorr J, Millward JM, Infante-Duarte C (2013) The antioxidant idebenone fails to prevent or attenuate chronic experimental autoimmune encephalomyelitis in the mouse. J Neuroimmunol 262(1-2):66-71. doi:10.1016/j.jneuroim.2013.07.002

25. Fischer MT, Sharma R, Lim JL, Haider L, Frischer JM, Drexhage J, Mahad D, Bradl M, van Horssen J, Lassmann H (2012) NADPH oxidase expression in active multiple sclerosis lesions in relation to oxidative tissue damage and mitochondrial injury. Brain 135(Pt 3):886-899. doi:10.1093/brain/aws012

26. Fischer MT, Wimmer I, Hoftberger R, Gerlach S, Haider L, Zrzavy T, Hametner S, Mahad D, Binder CJ, Krumbholz M, Bauer J, Bradl M, Lassmann H (2013) Disease-specific molecular events in cortical multiple sclerosis lesions. Brain $136(\mathrm{Pt}$ 6):1799-1815. doi:10.1093/brain/awt110

27. Fonseca-Kelly Z, Nassrallah M, Uribe J, Khan RS, Dine K, Dutt M, Shindler KS (2012) Resveratrol neuroprotection in a chronic mouse model of multiple sclerosis. Front Neurol 3:84. doi:10.338 9/fneur.2012.00084

28. Forge JK, Pedchenko TV, LeVine SM (1998) Iron deposits in the central nervous system of SJL mice with experimental allergic encephalomyelitis. Life Sci 63(25):2271-2284

29. Frischer JM, Bramow S, Dal-Bianco A, Lucchinetti CF, Rauschka $\mathrm{H}$, Schmidbauer M, Laursen H, Sorensen PS, Lassmann H (2009) The relation between inflammation and neurodegeneration in multiple sclerosis brains. Brain 132(Pt 5):1175-1189. doi:10.1093/brain/awp070

30. Gold R, Linington C, Lassmann H (2006) Understanding pathogenesis and therapy of multiple sclerosis via animal models: 70 years of merits and culprits in experimental autoimmune encephalomyelitis research. Brain 129(Pt 8):1953-1971. doi:10.1093/brain/aw1075

31. Grzybicki DM, Kwack KB, Perlman S, Murphy SP (1997) Nitric oxide synthase type II expression by different cell types in MHVJHM encephalitis suggests distinct roles for nitric oxide in acute versus persistent virus infection. J Neuroimmunol 73(1-2):15-27

32. Haghikia A, Hohlfeld R, Gold R, Fugger L (2013) Therapies for multiple sclerosis: translational achievements and outstanding needs. Trends Mol Med 19(5):309-319. doi:10.1016/j.molmed.2013.03.004

33. Haider L, Fischer MT, Frischer JM, Bauer J, Hoftberger R, Botond G, Esterbauer H, Binder CJ, Witztum JL, Lassmann H (2011) Oxidative damage in multiple sclerosis lesions. Brain $134(\mathrm{Pt}$ 7):1914-1924. doi:10.1093/brain/awr128

34. Hallgren B, Sourander P (1958) The effect of age on the non-haemin iron in the human brain. J Neurochem 3(1):41-51

35. Hametner S, Wimmer I, Haider L, Pfeifenbring S, Bruck W, Lassmann H (2013) Iron and neurodegeneration in the multiple sclerosis brain. Ann Neurol. doi:10.1002/ana.23974

36. Haring JS, Pewe LL, Perlman S (2001) High-magnitude, virusspecific CD4 T-cell response in the central nervous system of coronavirus-infected mice. J Virol 75(6):3043-3047. doi:10.112 8/JVI.75.6.3043-3047.2001

37. Higashi Y, Segawa S, Matsuo T, Nakamura S, Kikkawa Y, Nishida K, Nagasawa K (2011) Microglial zinc uptake via zinc transporters induces ATP release and the activation of microglia. Glia 59(12):1933-1945. doi:10.1002/glia.21235

38. Hoftberger R, Fink S, Aboul-Enein F, Botond G, Olah J, Berki T, Ovadi J, Lassmann H, Budka H, Kovacs GG (2010) Tubulin polymerization promoting protein (TPPP/p25) as a marker for oligodendroglial changes in multiple sclerosis. Glia 58(15):18471857. doi:10.1002/glia.21054

39. Hossain MM, Sonsalla PK, Richardson JR (2013) Coordinated role of voltage-gated sodium channels and the $\mathrm{Na} / \mathrm{H}$ exchanger in sustaining microglial activation during inflammation. Toxicol Appl Pharmacol. doi:10.1016/j.taap.2013.09.011

40. Kauppinen TM, Higashi Y, Suh SW, Escartin C, Nagasawa K, Swanson RA (2008) Zinc triggers microglial activation. J Neurosci 28(22):5827-5835. doi:10.1523/JNEUROSCI.1236-08.2008

41. Kipp M, Clarner T, Dang J, Copray S, Beyer C (2009) The cuprizone animal model: new insights into an old story. Acta Neuropathol 118(6):723-736. doi:10.1007/s00401-009-0591-3

42. Kolasinski J, Stagg CJ, Chance SA, Deluca GC, Esiri MM, Chang EH, Palace JA, McNab JA, Jenkinson M, Miller KL, Johansen-Berg H (2012) A combined post-mortem magnetic resonance imaging and quantitative histological study of multiple sclerosis pathology. Brain 135(Pt 10):2938-2951. doi:10.1093/ brain/aws 242

43. Koprowski H, Zheng YM, Heber-Katz E, Fraser N, Rorke L, Fu ZF, Hanlon C, Dietzschold B (1993) In vivo expression of inducible nitric oxide synthase in experimentally induced neurologic diseases. Proc Natl Acad Sci USA 90(7):3024-3027

44. Korner H, Schliephake A, Winter J, Zimprich F, Lassmann H, Sedgwick J, Siddell S, Wege H (1991) Nucleocapsid or spike protein-specific $\mathrm{CD}^{4+} \mathrm{T}$ lymphocytes protect against coronavirus-induced encephalomyelitis in the absence of $\mathrm{CD}^{8+} \mathrm{T}$ cells. $\mathrm{J}$ Immunol 147(7):2317-2323

45. Lassmann H (2011) Review: the architecture of inflammatory demyelinating lesions: implications for studies on pathogenesis. Neuropathol Appl Neurobiol 37(7):698-710. doi:10.1111/j.1365-2990.2011.01189.x

46. Lassmann H, Bruck W, Lucchinetti CF (2007) The immunopathology of multiple sclerosis: an overview. Brain Pathol 17(2):210-218. doi:10.1111/j.1750-3639.2007.00064.x

47. Lassmann H, van Horssen J, Mahad D (2012) Progressive multiple sclerosis: pathology and pathogenesis. Nat Rev Neurol 8(11):647-656. doi:10.1038/nrneurol.2012.168

48. LeVine SM, Maiti S, Emerson MR, Pedchenko TV (2002) Apoferritin attenuates experimental allergic encephalomyelitis in SJL mice. Dev Neurosci 24(2-3):177-183 (pii:65694)

49. Lijia Z, Zhao S, Wang X, Wu C, Yang J (2012) A self-propelling cycle mediated by reactive oxide species and nitric oxide exists in LPS-activated microglia. Neurochem Int 61(7):1220-1230. doi:10.1016/j.neuint.2012.09.002

50. Lim H, Kim D, Lee SJ (2013) Toll-like receptor 2 mediates peripheral nerve injury-induced NADPH oxidase 2 expression in spinal cord microglia. J Biol Chem 288(11):7572-7579. doi:10.1074/jbc.M112.414904

51. Lin MT, Hinton DR, Marten NW, Bergmann CC, Stohlman SA (1999) Antibody prevents virus reactivation within the central nervous system. J Immunol 162(12):7358-7368

52. Lipton HL, Liang Z, Hertzler S, Son KN (2007) A specific viral cause of multiple sclerosis: one virus, one disease. Ann Neurol 61(6):514-523. doi:10.1002/ana.21116

53. Lopes KO, Sparks DL, Streit WJ (2008) Microglial dystrophy in the aged and Alzheimer's disease brain is associated with ferritin immunoreactivity. Glia 56(10):1048-1060. doi:10.1002/ glia.20678

54. Mahad D, Ziabreva I, Lassmann H, Turnbull D (2008) Mitochondrial defects in acute multiple sclerosis lesions. Brain $131(\mathrm{Pt}$ 7):1722-1735. doi:10.1093/brain/awn105 
55. Mao P, Manczak M, Shirendeb UP, Reddy PH (2013) MitoQ, a mitochondria-targeted antioxidant, delays disease progression and alleviates pathogenesis in an experimental autoimmune encephalomyelitis mouse model of multiple sclerosis. Biochim Biophys Acta 1832(12):2322-2331. doi:10.1016/j.bbadis.2013.09.005

56. Marik C, Felts PA, Bauer J, Lassmann H, Smith KJ (2007) Lesion genesis in a subset of patients with multiple sclerosis: a role for innate immunity? Brain 130(Pt 11):2800-2815. doi:10.1093/ brain/awm 236

57. Meguro R, Asano Y, Odagiri S, Li C, Iwatsuki H, Shoumura K (2007) Nonheme-iron histochemistry for light and electron microscopy: a historical, theoretical and technical review. Arch Histol Cytol 70(1):1-19

58. Misko TP, Trotter JL, Cross AH (1995) Mediation of inflammation by encephalitogenic cells: interferon gamma induction of nitric oxide synthase and cyclooxygenase 2. J Neuroimmunol 61(2):195-204

59. Mitchell KM, Dotson AL, Cool KM, Chakrabarty A, Benedict SH, LeVine SM (2007) Deferiprone, an orally deliverable iron chelator, ameliorates experimental autoimmune encephalomyelitis. Mult Scler 13(9):1118-1126. doi:10.1177/1352458507078916

60. Moreno B, Jukes JP, Vergara-Irigaray N, Errea O, Villoslada P, Perry VH, Newman TA (2011) Systemic inflammation induces axon injury during brain inflammation. Ann Neurol 70(6):932942. doi:10.1002/ana.22550

61. Nam JH, Park KW, Park ES, Lee YB, Lee HG, Baik HH, Kim YS, Maeng S, Park J, Jin BK (2012) Interleukin-13/-4-induced oxidative stress contributes to death of hippocampal neurons in abeta1-42-treated hippocampus in vivo. Antioxid Redox Signal 16(12):1369-1383. doi:10.1089/ars.2011.4175

62. Nikic I, Merkler D, Sorbara C, Brinkoetter M, Kreutzfeldt M, Bareyre FM, Bruck W, Bishop D, Misgeld T, Kerschensteiner M (2011) A reversible form of axon damage in experimental autoimmune encephalomyelitis and multiple sclerosis. Nat Med 17(4):495-499. doi:10.1038/nm.2324

63. Okuda Y, Nakatsuji Y, Fujimura H, Esumi H, Ogura T, Yanagihara T, Sakoda S (1995) Expression of the inducible isoform of nitric oxide synthase in the central nervous system of mice correlates with the severity of actively induced experimental allergic encephalomyelitis. J Neuroimmunol 62(1):103-112

64. Palinski W, Horkko S, Miller E, Steinbrecher UP, Powell HC, Curtiss LK, Witztum JL (1996) Cloning of monoclonal autoantibodies to epitopes of oxidized lipoproteins from apolipoprotein E-deficient mice. Demonstration of epitopes of oxidized low density lipoprotein in human plasma. J Clin Invest 98(3):800-814. doi:10.1172/JCI118853

65. Park KW, Baik HH, Jin BK (2008) Interleukin-4-induced oxidative stress via microglial NADPH oxidase contributes to the death of hippocampal neurons in vivo. Curr Aging Sci 1(3):192-201

66. Park KW, Baik HH, Jin BK (2009) IL-13-induced oxidative stress via microglial NADPH oxidase contributes to death of hippocampal neurons in vivo. J Immunol 183(7):4666-4674. doi:10. 4049/jimmunol.0803392

67. Pedchenko TV, LeVine SM (1998) Desferrioxamine suppresses experimental allergic encephalomyelitis induced by MBP in SJL mice. J Neuroimmunol 84(2):188-197

68. Perry VH, Teeling J (2013) Microglia and macrophages of the central nervous system: the contribution of microglia priming and systemic inflammation to chronic neurodegeneration. Semin Immunopathol 35(5):601-612. doi:10.1007/s00281-013-0382-8

69. Pewe L, Haring J, Perlman S (2002) CD4 T-cell-mediated demyelination is increased in the absence of gamma interferon in mice infected with mouse hepatitis virus. J Virol 76(14):7329-7333

70. Pewe L, Perlman S (2002) Cutting edge: CD8 T cell-mediated demyelination is IFN-gamma dependent in mice infected with a neurotropic coronavirus. J Immunol 168(4):1547-1551
71. Piddlesden S, Lassmann H, Laffafian I, Morgan BP, Linington C (1991) Antibody-mediated demyelination in experimental allergic encephalomyelitis is independent of complement membrane attack complex formation. Clin Exp Immunol 83(2):245-250

72. Prineas JW, Kwon EE, Cho ES, Sharer LR, Barnett MH, Oleszak EL, Hoffman B, Morgan BP (2001) Immunopathology of secondary-progressive multiple sclerosis. Ann Neurol 50(5):646-657

73. Qi X, Lewin AS, Sun L, Hauswirth WW, Guy J (2007) Suppression of mitochondrial oxidative stress provides long-term neuroprotection in experimental optic neuritis. Invest Ophthalmol Vis Sci 48(2):681-691. doi:10.1167/iovs.06-0553

74. Qin J, Goswami R, Balabanov R, Dawson G (2007) Oxidized phosphatidylcholine is a marker for neuroinflammation in multiple sclerosis brain. J Neurosci Res 85(5):977-984. doi:10.1002/jnr.21206

75. Rackova L (2013) Cholesterol load of microglia: contribution of membrane architecture changes to neurotoxic power? Arch Biochem Biophys 537(1):91-103. doi:10.1016/j.abb.2013.06.015

76. Raivich G, Bohatschek M, Kloss CU, Werner A, Jones LL, Kreutzberg GW (1999) Neuroglial activation repertoire in the injured brain: graded response, molecular mechanisms and cues to physiological function. Brain Res Brain Res Rev 30(1):77-105

77. Rathore KI, Kerr BJ, Redensek A, Lopez-Vales R, Jeong SY, Ponka P, David S (2008) Ceruloplasmin protects injured spinal cord from iron-mediated oxidative damage. J Neurosci 28(48):12736-12747. doi:10.1523/JNEUROSCI.3649-08.2008

78. Ruuls SR, Bauer J, Sontrop K, Huitinga I, t Hart BA, Dijkstra CD (1995) Reactive oxygen species are involved in the pathogenesis of experimental allergic encephalomyelitis in Lewis rats. J Neuroimmunol 56(2):207-217

79. Sahrbacher UC, Lechner F, Eugster HP, Frei K, Lassmann H, Fontana A (1998) Mice with an inactivation of the inducible nitric oxide synthase gene are susceptible to experimental autoimmune encephalomyelitis. Eur J Immunol 28(4):1332-1338. doi:10.1002/(SICI)1521-4141(199804)28:04<1332:AIDIMMU1332>3.0.CO;2-G

80. Saxena A, Bauer J, Scheikl T, Zappulla J, Audebert M, Desbois S, Waisman A, Lassmann H, Liblau RS, Mars LT (2008) Cutting edge: multiple sclerosis-like lesions induced by effector CD8 T cells recognizing a sequestered antigen on oligodendrocytes. J Immunol 181(3):1617-1621

81. Schreibelt G, van Horssen J, van Rossum S, Dijkstra CD, Drukarch B, de Vries HE (2007) Therapeutic potential and biological role of endogenous antioxidant enzymes in multiple sclerosis pathology. Brain Res Rev 56(2):322-330. doi:10.1016/j.brainres rev.2007.07.005

82. Schulz K, Vulpe CD, Harris LZ, David S (2011) Iron efflux from oligodendrocytes is differentially regulated in gray and white matter. J Neurosci 31(37):13301-13311. doi:10.1523/JNEURO SCI.2838-11.2011

83. Spitsin SV, Scott GS, Mikheeva T, Zborek A, Kean RB, Brimer CM, Koprowski H, Hooper DC (2002) Comparison of uric acid and ascorbic acid in protection against EAE. Free Radic Biol Med 33(10):1363-1371

84. Stohlman SA, Hinton DR, Parra B, Atkinson R, Bergmann CC (2008) CD4 T cells contribute to virus control and pathology following central nervous system infection with neurotropic mouse hepatitis virus. J Virol 82(5):2130-2139. doi:10.1128/JVI.01762-07

85. Storch MK, Stefferl A, Brehm U, Weissert R, Wallstrom E, Kerschensteiner M, Olsson T, Linington C, Lassmann H (1998) Autoimmunity to myelin oligodendrocyte glycoprotein in rats mimics the spectrum of multiple sclerosis pathology. Brain Pathol 8(4):681-694

86. Streit WJ, Sammons NW, Kuhns AJ, Sparks DL (2004) Dystrophic microglia in the aging human brain. Glia 45(2):208-212. doi:10.1002/glia.10319 
87. Taoufik E, Tseveleki V, Chu SY, Tselios T, Karin M, Lassmann H, Szymkowski DE, Probert L (2011) Transmembrane tumour necrosis factor is neuroprotective and regulates experimental autoimmune encephalomyelitis via neuronal nuclear factor-kappaB. Brain 134(Pt 9):2722-2735. doi:10.1093/brain/awr203

88. Tschen SI, Bergmann CC, Ramakrishna C, Morales S, Atkinson R, Stohlman SA (2002) Recruitment kinetics and composition of antibody-secreting cells within the central nervous system following viral encephalomyelitis. J Immunol 168(6):2922-2929

89. Van Dam AM, Bauer J, Man AHWK, Marquette C, Tilders FJ, Berkenbosch F (1995) Appearance of inducible nitric oxide synthase in the rat central nervous system after rabies virus infection and during experimental allergic encephalomyelitis but not after peripheral administration of endotoxin. J Neurosci Res 40(2):251-260. doi:10.1002/jnr.490400214

90. van der Goes A, Brouwer J, Hoekstra K, Roos D, van den Berg TK, Dijkstra CD (1998) Reactive oxygen species are required for the phagocytosis of myelin by macrophages. J Neuroimmunol 92(1-2):67-75

91. van Horssen J, Singh S, van der Pol S, Kipp M, Lim JL, Peferoen L, Gerritsen W, Kooi EJ, Witte ME, Geurts JJ, de Vries HE, Peferoen-Baert R, van den Elsen PJ, van der Valk P, Amor S (2012) Clusters of activated microglia in normal-appearing white matter show signs of innate immune activation. J Neuroinflamm 9:156. doi:10.1186/1742-2094-9-156
92. Van Strien ME, Baron W, Bakker EN, Bauer J, Bol JG, Breve JJ, Binnekade R, Van Der Laarse WJ, Drukarch B, Van Dam AM (2011) Tissue transglutaminase activity is involved in the differentiation of oligodendrocyte precursor cells into myelin-forming oligodendrocytes during CNS remyelination. Glia 59(11):16221634. doi:10.1002/glia.21204

93. Wege H, Dorries R (1984) Hybridoma antibodies to the murine coronavirus JHM: characterization of epitopes on the peplomer protein (E2). J Gen Virol 65(Pt 11):1931-1942

94. Wege H, Schluesener H, Meyermann R, Barac-Latas V, Suchanek G, Lassmann H (1998) Coronavirus infection and demyelination. Development of inflammatory lesions in Lewis rats. Adv Exp Med Biol 440:437-444

95. Wiendl H, Hohlfeld R (2009) Multiple sclerosis therapeutics: unexpected outcomes clouding undisputed successes. Neurology 72(11):1008-1015. doi:10.1212/01.wnl.0000344417.42972.54

96. Wu GF, Perlman S (1999) Macrophage infiltration, but not apoptosis, is correlated with immune-mediated demyelination following murine infection with a neurotropic coronavirus. J Virol 73(10):8771-8780

97. Zimprich F, Winter J, Wege H, Lassmann H (1991) Coronavirus induced primary demyelination: indications for the involvement of a humoral immune response. Neuropathol Appl Neurobiol 17(6):469-484 